\title{
Development of a test method for transformation of veterinary pharmaceuticals and biocides in anaerobic liquid manure
}

\author{
Thomas Junker ${ }^{1 *}\left(\mathbb{D}\right.$, Cornelia Atorf $^{2}$, Silvia Berkner ${ }^{3}$, Rolf-Alexander Düring ${ }^{4}$, Dieter Hennecke ${ }^{2}$, \\ Monika Herrchen², Sabine Konradii ${ }^{3}$ Ute Merrettig-Bruns ${ }^{5}$, Jörg Römbke' ${ }^{1}$, Julia Wagner ${ }^{4}$ \\ and Karlheinz Weinfurtner ${ }^{2}$
}

\begin{abstract}
Background: Spreading of manure on agricultural soils represents an important pathway by which veterinary medicinal and biocidal products enter the environment. To assess their environmental impact in the context of authorization processes, experimental testing of transformation of these compounds in manure is considered in regulatory guidance documents. However, there is no standardized experimental test method available so far. To fill this gap, an experimental test method was developed to examine transformation in liquid cattle and pig manure.

Results: To account for manure specifics and for a possible influence of manure parameters on transformation rates, a comprehensive data acquisition and statistical analysis were performed. To address the variability of liquid manure of different type and origin, 30 manures were sampled and characterized. Thereof, three cattle and three pig manures were selected to perform anaerobic transformation studies with two radiolabeled veterinary medicinal active substances $\left({ }^{14} \mathrm{C}\right.$-salicylic acid and ${ }^{14} \mathrm{C}$-paracetamol) and a confidential radiolabeled ${ }^{114} \mathrm{C}$-biocide $\mathrm{B}^{\prime \prime}$ serving as test compounds. Spatial and seasonal variability of manure parameters was quantified, and a sampling technique to obtain homogenous manure samples was developed. Transformation studies with six replicates per sampling point were conducted to examine the influence of test setup, of manure storage conditions, and of parameter variations between manure of the same species and of different species on half-lives, formation of extractable and non-extractable residues and mineralization rates. Finally, a test design was established that yields reproducible results for transformation studies in liquid cattle and pig manure under anaerobic conditions.
\end{abstract}

Conclusions: Results give a reliable basis for an experimental test method to perform anaerobic transformation studies in liquid cattle and pig manure. The developed test method comprises detailed guidance on selection of sampling date and site, collection from manure tank, storage duration and temperature in the laboratory, duration of manure acclimation period, and the incubation system design. It proved to give reproducible results in a validation ring test performed in a follow-up project and is planned to be submitted as draft test guideline for approval by the OECD.

Keywords: Transformation, Manure, Veterinary medicinal product, Pharmaceutical, Biocide, Degradation

${ }^{*}$ Correspondence: th-junker@ect.de

'ECT Oekotoxikologie GmbH, 65439 Flörsheim, Germany

Full list of author information is available at the end of the article

\section{Background}

Veterinary medicinal products (VMPs) are frequently applied in livestock farming and up to $90 \%$ of the active ingredients are excreted unchanged by the treated

\section{Springer Open}

(c) The Author(s) 2020. This article is licensed under a Creative Commons Attribution 4.0 International License, which permits use, sharing, adaptation, distribution and reproduction in any medium or format, as long as you give appropriate credit to the original author(s) and the source, provide a link to the Creative Commons licence, and indicate if changes were made. The images or other third party material in this article are included in the article's Creative Commons licence, unless indicated otherwise in a credit line to the material. If material is not included in the article's Creative Commons licence and your intended use is not permitted by statutory regulation or exceeds the permitted use, you will need to obtain permission directly from the copyright holder. To view a copy of this licence, visit http://creativeco mmons.org/licenses/by/4.0/. 
animals [1]. In addition, biocides used for livestock treatment and stable disinfection treatment are transferred into liquid manure (e.g. [2, 3]). After manure storage, VMPs and biocides enter the environment when manure is spread onto agricultural soils for fertilization purposes $[4,5]$. For authorization of VMPs and biocides, an environmental impact assessment is required. Regulatory guidance documents include studies on transformation of these compounds in soil and manure [6]. Current guidance, e.g. guideline on determining the fate of veterinary medicinal products in manure [7], takes transformation in stored manure into account. However, the guidance only contains basic regulatory requirements. No standardized experimental test method is currently available, although it is crucial to have a harmonized and validated test method to obtain reliable and comparable data [8]. For example, technical details on how to homogeneously sample liquid manure from a manure tank or lagoon, and on how to measure endpoints such as mineralization, amount of non-extractable residues (NER), and disappearance half-life time of parent compound ( $\mathrm{DT}_{50}$ values) are not given in this regulatory guidance document [7]. Beyond that, it is insufficiently known as to whether and how certain aspects, e.g. manure storage conditions and type and origin of manure, might influence the rate of transformation.

When designing a test system for transformation of chemical substances in manure, specifics of the matrix have to be considered. Weinfurtner [9] carried out a literature study to acquire information on the variability of the composition of different types of anaerobic liquid manure with regard to species and production type, and thus to gather information on the conditions that prevail in manure storage tanks. It was concluded that in the European Union anaerobic (semi-) liquid manure is the predominant type of manure with regional variations. Furthermore, it was obvious from this literature study that the availability of data for matrix parameters of manures is highly variable. In a literature study carried out by Wohde et al. [8], only a limited number of studies on the transformation of VMPs and particularly biocides in liquid manure could be identified. Beyond that, available transformation studies showed large variations with regard to experimental setup (e.g. static, semi-static, flow-through), type and source of manure and test conditions (e.g. dry matter content, redox potential). The authors conclude that the investigated manure characterization is not accomplished sufficiently or comparably in most studies, even though manure parameters influence the results of transformation studies. Former work on laboratory transformation tests for chemicals in liquid manure focused on reference-manure samples (prepared by moistening excrement samples; e.g. [10]) and simplified experiments allowing the screening of the dissipation of a large number of active substances in manure (e.g. [11]).

Against this background, a test method to study the transformation of chemicals (VMPs and biocides) in anaerobic liquid cattle and pig manure was developed, taking into account experiences from simulation type studies on transformation in soil and in water/sediment systems (test guidelines OECD 307 [12] and OECD 308 [13]) and adapting their test design to the specific requirements of the matrix manure. Using ${ }^{14} \mathrm{C}$-radiolabeled test compounds, a complete mass balance can be established and different dissipation processes like primary degradation (i.e. detection, identification and quantification of parent), formation of transformation products, mineralization (i.e. to ${ }^{14} \mathrm{CO}_{2}$ and ${ }^{14} \mathrm{CH}_{4}$ ), and formation of extractable and non-extractable residues can be distinguished.

This paper describes the development of a test method for transformation studies of veterinary pharmaceuticals and biocides in anaerobic liquid manure, which was used as basis for the validation in the framework of an international ring test described by Junker et al. [14]. The development was a step-by-step procedure in which several issues were addressed.

In the first step, preliminary studies were performed with regard to manure characterization, sampling, acclimation and storage. A standardized method was developed to homogenize manure both in the manure storage tank and in the laboratory prior to performing transformation studies. This standardization was crucial to obtain reproducible results.

Subsequently, two anaerobic intra-laboratory test series with ${ }^{14} \mathrm{C}$-labeled compounds were performed to examine the influence of test setup (flow-through vs. semistatic, flow rate, amount of manure) on mineralization rates (test series 1 ) and the influence of type and origin of manure on transformation rates (test series 2).

The results and experience gained during method development, the validation ring test [14-17] and discussions at two technical workshops and several international meetings, were used to draft a test protocol on anaerobic transformation of chemicals in liquid manure [14] to provide a basis for international harmonization and standardization, e.g. in the framework of the OECD.

\section{Methods}

\section{Manure sampling site selection}

To develop a procedure for obtaining homogeneous manure samples from a tank and to get an overview on the spatial and seasonal variability of manure parameters, cattle manure was sampled from different regions and at different seasons in Germany. The manure sampling 
campaign was performed in 2010/2011. Cattle manure was sampled in winter (December to January; herein referred to as "winter manure") and in summer (April to July; herein referred to as "summer manure"). In total, summer and winter manure obtained from 10 different sites were subjected to characterization. Further information is given in Table 1. Pig manure was collected from regions in Germany which are important for pig rearing. The manure was sampled in the period from November 2011 to September 2012. Three sites each in Bavaria (codes: BAY_1p, BAY_2p, BAY_3p) and North-RhineWestphalia (codes: NRW_1p, NRW _2p, NRW_3p) was selected. Manure temperature, redox potential and $\mathrm{pH}$ values were measured on-site.

\section{Manure collection}

Prior to collection, the liquid manure was homogenized by mixing in the respective manure storage tank. For mixing, devices either being installed in the tank or external devices were used. Mixing was performed for $1 \mathrm{~h}$, independent from tank volume, and by applying the same procedure as used by the farmer prior to manure spreading. Liquid pig manure and cattle manure required different handling: pig manure was stirred immediately before sampling as separation into liquid and solid phase easily occurs, cattle manure was stirred the day before sampling. After mixing, the subsamples were collected from the tank by appropriate equipment, namely a ladle with a large beaker or a large beaker on a rope. The ladle with the beaker was put into the manure storage tank and turned slightly into various directions. Thereafter, the equipment was withdrawn from the tank and the manure filled into containers. Filling up to approximately three quarters of maximum container volume was proven to be appropriate as the volume of the manure expands due to gas, which is generated by continuous microbial activity. The containers were closed tightly allowing for expansion of gas by connecting a tube with a fermentation air lock to an outlet in the container.

To examine if a reliable and representative sampling of manure is feasible, which is a prerequisite for subsequent transformation studies, the homogeneity of manure collected according to the described sampling procedure was tested. Therefore, 10 replicates of cattle manure were sampled at the sites NRW_1c and NRW_2c each, both in winter and in summer. To also investigate differences in parameters of manure from different spatial origin, the results obtained for 10 sites (one replicate each) were subjected to COV calculation. All replicates were analyzed for the parameters dry matter content (\%), ammonium nitrogen $(\mathrm{mg} / \mathrm{kg} \mathrm{fw})$, total nitrogen $(\mathrm{mg} / \mathrm{kg} \mathrm{fw})$, and organic carbon content (\% fw).

\section{Manure characterization}

EMA [7] requires the characterization of manure at various stages of a transformation study by measuring several parameters. The following paragraphs give an overview of the determined manure parameters, the sampling regime and the standardized test methods used for measurements (for details, see also Additional file 1: Table S1).

Table 1 Description of below ground cattle manure sampling sites

\begin{tabular}{|c|c|c|c|c|c|c|}
\hline \multirow[t]{2}{*}{ Code } & \multirow{2}{*}{$\begin{array}{l}\text { Manure storage tank } \\
\text { volume }\left(\mathrm{m}^{3}\right)\end{array}$} & \multicolumn{3}{|l|}{ Stock } & \multirow{2}{*}{$\begin{array}{l}\text { Last treatment } \\
\text { before } X \text { months }\end{array}$} & \multirow[t]{2}{*}{ Feeding } \\
\hline & & Beef cattle & Dairy cow & Young cattle & & \\
\hline$N_{R} W^{a} \_1 c$ & 100 & - & 100 & 45 & - & Pasture, silage (pasture) \\
\hline NRW_2C & 100 & - & 80 & 30 & $3-6$ & Pasture, silage (pasture), mash \\
\hline NRW_3c & 100 & - & 80 & - & $>6$ & Silage (pasture, corn), shred \\
\hline NRW_4c & 80 & - & 900 & - & $>6$ & Silage (corn) \\
\hline NRW_5c & 100 & 200 & - & - & $>6$ & $\begin{array}{l}\text { Silage (corn), food for fatten- } \\
\text { ing (e.g. rape shred) }\end{array}$ \\
\hline $\mathrm{NDS}^{\mathrm{b}} \_1 \mathrm{c}$ & 70 & - & 50 & $50^{c}$ & $3-6$ & Silage (pasture, corn) \\
\hline NDS_2C & 100 & - & 170 & $170^{c}$ & $>6$ & Silage (pasture), straw \\
\hline $\mathrm{He}^{\mathrm{d}}{ }_{1} \mathrm{c}$ & 70 & - & 90 & 45 & $3-6$ & Pasture, silage (corn) \\
\hline BAYe_1c & $250^{f}$ & - & 65 & 30 & $>6$ & Cereals, silage (corn) \\
\hline BAY_2C & $2 \times 250$ & - & 40 & 30 & $>6$ & Silage (pasture, corn), hay \\
\hline
\end{tabular}

a NRW North-Rhine-Westphalia

b NDS lower saxony

c Calves

d He Hesse

e BAY Bavaria

${ }^{f}$ Open storage tank 


\section{pH value}

The $\mathrm{pH}$ value was measured both, directly in manure after sampling at the sampling location (on-site) and in the laboratory (off-site) following a standard test method [18]. The $\mathrm{pH}$ values are expressed with accuracy of 0.1 units.

\section{Redox potential}

The redox potential is directly measured in manure sample after sampling on-site. The value of redox potential is expressed in $\mathrm{mV}$ with accuracy of $1 \mathrm{mV}$ [19].

\section{Dry matter $(\mathrm{dm})$ content}

Manure samples (50-80 g) were dried in an oven for at least $12 \mathrm{~h}$ at $105 \pm 5{ }^{\circ} \mathrm{C}$ to constant mass. The mass difference of a sample before and after the drying procedure was used to calculate the dry mass content that is expressed in percentage of the fresh weight with accuracy of $\pm 0.1 \%$ in accordance with [20].

\section{Loss of ignition/organic matter content}

The dried manure samples were incinerated in a muffle furnace for at least $1 \mathrm{~h}$ at $550 \pm 25^{\circ} \mathrm{C}$. The mass difference of a sample before and after incineration was used to calculate the organic matter content that is expressed in $\% \mathrm{dm}$ with an accuracy of $\pm 0.1 \%$ [21].

\section{Total organic carbon (TOC) content}

Total organic carbon content was analyzed using a CHNanalyzer (vario max $\mathrm{CHN}$, elementar). To remove the total inorganic carbon (TIC), the sample was acidified prior to the measurement. The carbon present in dried manure was then oxidized to carbon dioxide by heating up to at least $900{ }^{\circ} \mathrm{C}$ in an oxygen atmosphere. The released amount of carbon dioxide was measured by infrared detection. The dry matter content was used to re-calculate the data to \% fresh weight (fw). The organic carbon content is expressed in \% fw with an accuracy of $\pm 0.1 \%[22]$.

\section{Total nitrogen content}

The total nitrogen content of wet manure samples (up to $6 \mathrm{~g}$ ) was determined by Kjeldahl digestion (Turbotherm, Gerhardt) that transfers the nitrogen containing compounds (amines, proteins) into ammonium. The total nitrogen content is expressed in $\mathrm{mg} / \mathrm{kg} \mathrm{dm}$ with accuracy of $1 \mathrm{mg} / \mathrm{kg}$ [23].

\section{Ammonium nitrogen content}

A wet manure sample (up to $5 \mathrm{~g}$ ) was alkalized by adding of sodium hydroxide ( $30 \%$ solution) and was distillated using an automatic distillation apparatus (Vapodest, Gerhardt). The released ammonia was trapped in $50 \mathrm{~mL}$ boric acid (20 g/L). Ammonium was titrated using standard volumetric sulphuric acid solution $(0.1 \mathrm{~mol} / \mathrm{L})$ and some drops of an indicator solution (mixed indicator 5, Merck). The ammonium nitrogen content is expressed in $\mathrm{mg} / \mathrm{kg}$ with accuracy of $1 \mathrm{mg} / \mathrm{kg}$ [24].

\section{Microbial activity}

The microbial activity was determined by measuring the mineralization of a readily degradable ${ }^{14} \mathrm{C}$-labeled compound under anaerobic conditions as developed by Bickert [25] and as mentioned in EMA [7]. ${ }^{14} \mathrm{C}$-glucose (CAS-No.: 50-99-7, radiochemical purity 99\%, specific radioactivity $9.4 \mathrm{GBq} / \mathrm{mmol}$, American Radiolabeled Chemicals, Inc., Lot no. II0105) was used as readily degradable substance. Nine blank manure subsamples without test item were treated in analogy to the samples used for the transformation study (i.e. acclimation of manure, anaerobic/methanogenic incubation conditions, temperature, and light conditions). $3 \times 3$ replicates were set up as the microbial activity was tested at start and end of the transformation study, and three further replicates were kept as reserves in case the transformation study needed to be prolonged. At the start and the end of the transformation study, the manure was treated with ${ }^{14} \mathrm{C}$-glucose. Treatment was done by the addition of approximately $800 \mu \mathrm{L}$ aqueous solution containing $0.8 \mu \mathrm{g}$ ${ }^{14} \mathrm{C}$-glucose (concentration in stock solution $1 \mu \mathrm{g} / \mathrm{mL}$; $50 \mathrm{kBq}$ in $800 \mu \mathrm{L}$ stock solution) to $50 \mathrm{~g}$ manure fresh weight. Thereafter, a constant, water saturated stream of nitrogen was passed over the manure at a rate of approximately $50-100 \mathrm{~mL} / \mathrm{min}$. Incubation of manure fortified with ${ }^{14} \mathrm{C}$-glucose was for 7 days. After 7 days, $\mathrm{NaOH}$-containing traps to measure mineralization were removed and radio-counted for trapped ${ }^{14} \mathrm{CO}_{2}$ and ${ }^{14} \mathrm{CH}_{4}$ (see under "incubation systems"). The removed traps were replaced by freshly filled traps. Thereafter, the manure subsamples were treated by addition of $10 \mathrm{~mL} 10 \% \mathrm{HCl}$ to strip potentially dissolved $\mathrm{CO}_{2}$ (or $\mathrm{HCO}_{3}{ }^{-} / \mathrm{CO}_{3}{ }^{2-}$ ). After addition of $10 \mathrm{~mL} 10 \% \mathrm{HCl}$, the incubation vessels were closed again and nitrogen was passed over for $3 \mathrm{~h}$. Samples were not stirred to avoid foaming. After $3 \mathrm{~h}$, $\mathrm{NaOH}$-filled traps were removed and radio-counted for additionally trapped ${ }^{14} \mathrm{CO}_{2}$. The amount of formed ${ }^{14} \mathrm{CO}_{2}$ and ${ }^{14} \mathrm{CH}_{4}$ after 7 days of ${ }^{14} \mathrm{C}$-glucose incubation was used as a measure of the biological activity of the manure at that respective stage of the transformation study.

\section{Storage of manure}

After sampling and before starting a transformation study, it is necessary to store the manure in the laboratory. Therefore, experiments were performed to identify suitable storage conditions. This was achieved by storing liquid cattle manure at different conditions 
and subsequently testing the microbial activity of the manure by measuring ${ }^{14} \mathrm{C}$-glucose mineralization 7 days after treatment (DAT) (see "Microbial activity" section). The results obtained for storage periods of 0 days (fresh manure), 28 days, 63 days, and 105 days and temperatures of $+4{ }^{\circ} \mathrm{C}$ and $+20^{\circ} \mathrm{C}$ after an acclimation period of 21 days were compared.

Anaerobic/methanogenic conditions were ensured by first passing nitrogen over the liquid manure and thereafter closing the container. Care had to be taken to allow gas, generated by biological activity during storage, to expand in order to avoid bursting of the storage container.

\section{Manure acclimation}

Prior to use for testing purposes, freshly collected or stored manure needs to be acclimated to the conditions under which the transformation study is going to be performed. This means the manure is filled into vessels to be acclimatized for a certain time period under anaerobic conditions at $20 \pm 2{ }^{\circ} \mathrm{C}$ in semi-static or flow-through systems. By acclimation for 3 days and 21 days, respectively, and a subsequent determination of the microbial activity of the manure, the influence of the duration of the acclimation period was investigated. Prior to acclimation, the manure was either freshly collected or stored for 56 days at $+4{ }^{\circ} \mathrm{C},+20{ }^{\circ} \mathrm{C}$ and $-20{ }^{\circ} \mathrm{C}$ (the latter for one replicate only). The microbial activity was tested by determining the mineralization of ${ }^{14} \mathrm{C}$-glucose after its incubation period of 7 days.

\section{Transformation studies setup}

Two VMPs and one biocide were used to examine the feasibility of the suggested test design, and the influence of manure of different type and origin on transformation rates and routes. To cover the most diverse set of different manures concerning origin, period stored in the tank and matrix parameters, such manure sampling sites were chosen which represented different geographic locations, and summer (April to November) and winter (December to March) manures (cf. Additional file 1: Tables S2 and S3 for details on manure characterization).

\section{Test series and test substances}

Two test series of transformation studies were run, which required the use of exemplary test substances. These test substances were selected from VMPs and biocides authorized for use in animal farming. Besides, regulatory relevance compounds were chosen based on the following selection criteria: the substances should not degrade immediately after application (e.g. $\mathrm{DT}_{50}<1$ day) to allow for feasible and reproducible sampling; the substances should not be persistent, which would result in a prolonged test period or lack of kinetic information; degradation should mainly be based on biological processes; requirements for chemical analyses should not be unreasonably high; the substances should be available as ${ }^{14} \mathrm{C}$-labeled compound and the position of the ${ }^{14} \mathrm{C}$-label should enable the detection of main transformation products.

Whereas non-labeled or labeled test chemicals can be used to measure the rate of dissipation of the parent compound, ${ }^{14} \mathrm{C}$-radiolabeled material is required for studying the pathway of transformation, for quantifying $\mathrm{CO}_{2}$ - and $\mathrm{CH}_{4}$-formation, formation of NER, screening for and quantification of transformation products and for establishing a mass balance. In addition, if a non-labeled test chemical is used, a background control or blank sample has to be analyzed, to exclude the presence of the test chemical or to quantify a possible background concentration of the test chemical in the manure.

The first test series studied the influence of the test system setup on the mineralization rate of ${ }^{14} \mathrm{C}$-salicylic acid (CAS-No. 69-72-2; radiochemical purity $99.0 \%$; specific radioactivity 4.0 MBq/mg; American Radiolabeled Chemicals, Inc.; Lot nos. IO1112, ARC 0287). Tested experimental setups were (i) use of a flow-through system (that means, continuously passing nitrogen over the manure samples) compared to use of a semi-static system (that means intermittently passing nitrogen over the manure samples); (ii) slow flow rate (constant stream of nitrogen of $50-200 \mathrm{~mL} / \mathrm{min}$ ) compared to fast flow rate $(>200 \mathrm{~mL} / \mathrm{min}$ ) in a flow-through system; (iii) incubation of $50 \mathrm{~g}$ manure compared to $300 \mathrm{~g}$ manure in a flowthrough system. Half-life times of mineralization rates $\left(\mathrm{DT}_{50 \text { MIN }}\right)$ were calculated as endpoints based on the formation of ${ }^{14} \mathrm{CO}_{2}$ and ${ }^{14} \mathrm{CH}_{4}$. Besides, the mass balance (recovery) at the end of the transformation study was determined and served as a quality check.

The second test series examined the influence of type and origin of manure on the transformation rate of ${ }^{14} \mathrm{C}$-salicylic acid, ${ }^{14} \mathrm{C}$-paracetamol (CAS-No. 103-902; radiochemical purity $99.2 \%$; specific radioactivity 18.8 MBq/mg; American Radiolabeled Chemicals, Inc.; Lot no. 153-064-077-A-20080611-DR) and a radiolabeled biocide ("biocide B"; the identity was classified as confidential by the owner of the substance; radiochemical purity $>99.0 \%$; specific radioactivity $4.44 \mathrm{MBq} / \mathrm{mg}$ ).

The test conditions used for the transformation studies in test series 1 and 2 are described in the following paragraphs and are summarized in Tables 2 and 3, respectively.

\section{Preparation of manure}

Before performing the transformation test, the manure was acclimated to test conditions. Prior to the start of the 
Table 2 Summary of test conditions used for transformation studies to investigate the influence of test setup on mineralization rates of ${ }^{14} \mathrm{C}$-salicylic acid in cattle and pig manure (Test series 1 )

\begin{tabular}{|c|c|c|c|}
\hline Parameter & Influence of test setup on minera & alization rates (Test series 1 ) & \\
\hline Variations in test setup & (i) Flow-through vs. semi-static & (ii) Slow flow vs. fast flow & (iii) Low vs. high amount of manure \\
\hline Details & $\begin{array}{l}\text { Flow-through: } 50-200 \mathrm{~mL} \text { min }^{-1} \\
\text { Semi-static: purged once/week }\end{array}$ & $\begin{array}{l}\text { Slow flow: } 50-200 \mathrm{~mL} / \mathrm{min} \\
\text { Fast flow: }>200 \mathrm{~mL} \mathrm{~min}-1\end{array}$ & $\begin{array}{l}\text { Low: } 50 \mathrm{~g} \text { manure fw } \\
\text { High: } 300 \mathrm{~g} \text { manure fw (slow flow-through) }\end{array}$ \\
\hline Test substance & ${ }^{14} \mathrm{C}$-salicylic acid & ${ }^{14} \mathrm{C}$-salicylic acid & ${ }^{14} \mathrm{C}$-salicylic acid \\
\hline Temperature & $20 \pm 2^{\circ} \mathrm{C}$ & $20 \pm 2^{\circ} \mathrm{C}$ & $20 \pm 2^{\circ} \mathrm{C}$ \\
\hline Light & Darkness & Darkness & Darkness \\
\hline Acclimation period & 21 days & 21 days & 21 days \\
\hline Type of manure & Cattle (c), pig (p) & Cattle (c), pig (p) & Cattle (c), pig (p) \\
\hline Manure sampling & 1 site: summer $(c, p)$ & 1 site: winter $(c, p)$ & 1 site: winter $(c, p)$ \\
\hline Dry matter content & $10 \pm 1 \%(c), 5 \pm 1 \%(p)$ & $10 \pm 1 \%(c), 5 \pm 1 \%(p)$ & $10 \pm 1 \%(c), 5 \pm 1 \%(p)$ \\
\hline Amount of manure & $50 \mathrm{~g} \mathrm{fw}$ & $50 \mathrm{~g} \mathrm{fw}$ & $50 \mathrm{~g} \mathrm{fw}$ or $300 \mathrm{~g} \mathrm{fw}$ \\
\hline Replicates per sampling & 6 (set in parallel) & 6 (set in parallel) & 6 (set in parallel) \\
\hline Test duration & 85 days $(c, p)$ & 91 days $(c), 85$ days $(p)$ & 91 days $(c), 85$ days $(p)$ \\
\hline Sampling time points & $\begin{array}{l}c: 3,7,14,21,35,42,49,56,63,85 \\
p: 3,7,14,21,35,42,49,56,63,85\end{array}$ & $\begin{array}{l}c: 3,7,14,21,29,35,42,49,56,63,70 \\
\quad 79,91 \\
p: 3,7,14,21,35,42,49,56,63,85\end{array}$ & $\begin{array}{l}c: 3,7,14,21,29,35,42,49,56,63,70,79,91 \\
p: 3,7,14,21,35,42,49,56,63,85\end{array}$ \\
\hline${ }^{14} \mathrm{CO}_{2} /{ }^{14} \mathrm{CH}_{4}$ quantification & Yes (each sampling point) & Yes (each sampling point) & Yes (each sampling point) \\
\hline Residue characterization & Yes (at the end) & Yes (at the end) & Yes (at the end) \\
\hline Abiotic/sterile controls & No & No & No \\
\hline Microbial activity testing & Yes (at start and end) & Yes (at start and end) & Yes (at start and end) \\
\hline Complete mass balance & Yes (at the end) & Yes (at the end) & Yes (at the end) \\
\hline Evaluation of kinetics & Yes (mineralization rate, $\mathrm{DT}_{50 \mathrm{mIN}}$ ) & Yes (mineralization rate, $\mathrm{DT}_{50 \mathrm{MIN}}$ ) & Yes (mineralization rate, $\mathrm{DT}_{50 \mathrm{MIN}}$ ) \\
\hline
\end{tabular}

Table 3 Summary of test conditions used for transformation studies to investigate the influence of type and origin of manure on transformation rates (Test series 2 )

\begin{tabular}{|c|c|c|c|}
\hline \multirow{2}{*}{$\begin{array}{l}\text { Parameter } \\
\text { Test setup }\end{array}$} & \multicolumn{3}{|c|}{ Influence of type and origin of manure on transformation rates (Test series 2) } \\
\hline & $\begin{array}{l}\text { Flow-through: slow flow }(50-200 \mathrm{~mL} / \\
\text { min) }\end{array}$ & $\begin{array}{l}\text { Flow-through: slow flow }(50-200 \mathrm{~mL} / \\
\text { min) }\end{array}$ & $\begin{array}{l}\text { Flow-through: slow flow (50-200 mL/ } \\
\text { min) }\end{array}$ \\
\hline Test substance & ${ }^{14} \mathrm{C}$-salicylic acid & ${ }^{14} \mathrm{C}$-paracetamol & ${ }^{14}$ C-biocide $B$ \\
\hline Temperature & $20 \pm 2{ }^{\circ} \mathrm{C}$ & $20 \pm 2{ }^{\circ} \mathrm{C}$ & $20 \pm 2{ }^{\circ} \mathrm{C}$ \\
\hline Light & Darkness & Darkness & Darkness \\
\hline Acclimation period & 21 days & 21 days & 21 days \\
\hline Type of manure & Cattle (c), pig (p) & Cattle (c), pig (p) & Cattle (c), pig (p) \\
\hline Manure sampling & $\begin{array}{l}3 \text { sites } \\
c: \text { winter + summer } \\
p \text { : winter/summer }\end{array}$ & $\begin{array}{l}3 \text { sites } \\
c: \text { summer } \\
p \text { : winter/summer }\end{array}$ & $\begin{array}{l}3 \text { sites } \\
c: \text { summer } \\
p: \text { summer }\end{array}$ \\
\hline Dry matter content & $10 \pm 1 \%(c), 5 \pm 1 \%(p)$ & $10 \pm 1 \%(c), 5 \pm 1 \%(p)$ & $10 \pm 1 \%(c), 5 \pm 1 \%(p)$ \\
\hline Amount of manure & $50 \mathrm{~g} \mathrm{fw}$ & $50 \mathrm{~g} \mathrm{fw}$ & $50 \mathrm{~g} \mathrm{fw}$ \\
\hline Replicates per sampling & 6 (set in series) & 6 (set in series) & 6 (set in series) \\
\hline Test duration & 36 days $(c, p)$ & 28 days $(\mathrm{c}), 41$ days $(\mathrm{p})$ & 105 days $(c, p)$ \\
\hline Sampling time points & $c, p: 0,3,7,14,21,28,36$ & $\begin{array}{l}c: 0,0.3,1,3,7,14,28 \\
p: 0,1,3,7,14,28,41\end{array}$ & $c, p: 0,7,21,42,63,84,105$ \\
\hline${ }^{14} \mathrm{CO}_{2} /{ }^{14} \mathrm{CH}_{4}$ quantification & Yes (each sampling point) & Yes (each sampling point) & Yes (each sampling point) \\
\hline Residue characterization & Yes (each sampling point) & Yes (each sampling point) & Yes (each sampling point) \\
\hline Abiotic/sterile controls & Yes (sampling at the end) & Yes (sampling at the end) & Yes (sampling at the end) \\
\hline Microbial activity testing & Yes (at start and end) & Yes (at start and end) & Yes (at start and end) \\
\hline Complete mass balance & Yes (each sampling point) & Yes (each sampling point) & Yes (each sampling point) \\
\hline Evaluation of kinetics & $\begin{array}{l}\text { Yes (dissipation rate of parent, } \mathrm{DT}_{50} \\
\mathrm{DT}_{90} \text { ) }\end{array}$ & $\begin{array}{l}\text { Yes (dissipation rate of parent, } \mathrm{DT}_{50 \prime} \\
\mathrm{DT}_{90} \text { ) }\end{array}$ & $\begin{array}{l}\text { Yes (dissipation rate of parent, } \mathrm{DT}_{50} \\
\mathrm{DT}_{90} \text { ) }\end{array}$ \\
\hline
\end{tabular}


acclimation period, the dry matter content of the manure was determined and adjusted to standardized values. The recommended dry matter content in cattle and pig manure is $10 \% \pm 1 \%$ and $5 \% \pm 1 \%$, respectively [7]. If the dry matter content of the original manure was below the recommended value, it was concentrated by careful centrifugation for $10 \mathrm{~min}$ at $740 \times g$. However, centrifugation does not only mean a removal of water but also of DOC and micro-organisms. Thus, the initial dry matter content should not be below $8 \%$ (cattle) or 3\% (pig). If this was not the case, fresh manure was collected. If dry matter content is too high, water (de-ionized water, bubbled with nitrogen for $30 \mathrm{~min}$ ) was added as needed. Pig manure was homogenized by using a knifetec mill (or similar apparatus) under anaerobic conditions (i.e. by gently passing a nitrogen stream over the manure while mixing) prior to adjustment of the dry matter content in order to obtain a fairly stable phase.

After the adjustment of the dry matter content, manure was homogenized and subsamples were directly filled into the incubation vessels, which were used both for manure acclimation phase and the transformation study itself. Pig manure was homogenized under anaerobic conditions by thoroughly mixing as described above. Cattle manure was homogenized by gently mixing using a glass bar and no additional measures to prevent introduction of oxygen were used during homogenization and filling into incubation vessels. This was not necessary because minor amounts of introduced oxygen were easily consumed by the microbial population.

\section{Incubation systems}

Transformation tests were conducted either in a flowthrough or semi-static system. The flow-through apparatus was a gas tight system of incubation vessel and traps set in sequence. Humidified nitrogen was gently passed over the liquid manure subsamples at flow rates of 50-200 $\mathrm{mL} / \mathrm{min}$ ("slow-flow") or-as an also tested alternative - of $>200 \mathrm{~mL} / \mathrm{min}$ ("fast flow"). First, the nitrogen was bubbled through water to humidify the gas. Thereafter, the humidified gas was passed over the manure subsamples. Six replicates were run. Once the gas has passed over the incubation flask, it was bubbled through two adsorption traps in sequence containing $2 \mathrm{M} \mathrm{NaOH}$ serving to sorb the evolving ${ }^{14} \mathrm{CO}_{2}$. Since the formation of ${ }^{14} \mathrm{CH}_{4}$ was expected in such an anaerobic system, the gas was furthermore passed through an oven at $850{ }^{\circ} \mathrm{C}$. ${ }^{14} \mathrm{CH}_{4}$ was catalytically (CuO-catalyst $+\mathrm{O}_{2}$ feeding to the tube) converted to ${ }^{14} \mathrm{CO}_{2}$, which again was trapped in a third $\mathrm{NaOH}$ trap. Frequently, i.e. at sampling and 14-day intervals, respectively, $\mathrm{NaOH}$-containing traps were removed and radio-counted for trapped ${ }^{14} \mathrm{CO}_{2}$. The removed traps were replaced by freshly filled ones.
At sampling, the manure subsamples were additionally treated by addition of $10 \mathrm{~mL} 10 \% \mathrm{HCl}$ to strip potentially dissolved $\mathrm{CO}_{2}$ (or $\mathrm{HCO}_{3}{ }^{-} / \mathrm{CO}_{3}{ }^{2-}$ ). After addition of $10 \mathrm{~mL} 10 \% \mathrm{HCl}$ the incubation vessels were closed again and nitrogen was passed over for $3 \mathrm{~h}$. Stability of the test substances against acidic hydrolysis was tested before. To verify whether the radioactivity captured in the $\mathrm{NaOH}$ traps 1 and 2 is ${ }^{14} \mathrm{CO}_{2}$ and not from potentially also formed volatile fatty acids (VFA), $\mathrm{Ba}^{14} \mathrm{CO}_{2}$ precipitation of the radioactivity was conducted. This was done by first radio-counting the solutions in $\mathrm{NaOH}$ traps 1 and 2. Thereafter, $20 \mathrm{~mL} 0.25 \mathrm{M} \mathrm{BaCl}_{2}$ was added to $10 \mathrm{~mL}$ aliquots of $\mathrm{NaOH}$ trapping solution from traps 1 and 2 each. Precipitation of $\mathrm{Ba}^{14} \mathrm{CO}_{2}$ occurred. Vessels were shaken, centrifuged and the supernatant was again radiocounted. The radioactive content in the supernatant after precipitation can be attributed to VFAs whereas the difference of radioactive content before precipitation minus radioactive content after precipitation can be attributed to evolved ${ }^{14} \mathrm{CO}_{2}$.

The setup for the semi-static system was in principle the same as for the flow-through system with the only exception of valves set before the incubation vessel and at the outlet of the second $\mathrm{NaOH}$-containing trap. Subsamples of the manure were filled into the incubation vessels. For a period of $1 \mathrm{~h}$, a gentle stream of nitrogen was passed over the manure to exclude air from the system. After flushing with nitrogen, the system was closed by closing the two valves. Periodically, e.g. once a week, the system was flushed for $3 \mathrm{~h}$ by passing a gentle stream of nitrogen over the manure samples. Formed ${ }^{14} \mathrm{CO}_{2}$, ${ }^{14} \mathrm{CH}_{4}$ and VFA were trapped directly or after conversion to $\mathrm{CO}_{2}$ and quantified as described for the flow-through apparatus.

\section{Test conditions}

During the whole test period, the manure samples were incubated in the dark at $20 \pm 2{ }^{\circ} \mathrm{C}$. Typical environmental temperatures observed in manure tanks are $10{ }^{\circ} \mathrm{C}$ for central/northern European countries [9]. In other regions, different temperatures might be considered typical. Therefore, results from laboratory tests (e.g. $\mathrm{DT}_{50}$ values) might have to be converted to environmentally relevant temperatures [26]. As stored liquid manure was found to be anaerobic/methanogenic (i.e. redox potentials ranging from -230 to $<-400 \mathrm{mV}$ [9]), tests were conducted under anaerobic conditions, as demonstrated by measured redox potentials $(\mathrm{Eh}) \leq-100 \mathrm{mV}$ throughout the test.

\section{Abiotic controls (sterile samples)}

For information on the abiotic transformation of the test substance, sterile controls were included. Sampling 
of sterile controls was at the end of the transformation study. Manure was sterilized by autoclaving twice for $15 \mathrm{~min}$ at $121{ }^{\circ} \mathrm{C}$ (Systec DX-65 Autoclave). To avoid foaming, vessels were pre-heated overnight at $100{ }^{\circ} \mathrm{C}$ in a drying cabinet. The application solution was sterilized by passing over a sterile filter. Application of the test substance was under sterile conditions using a clean-bench. Thereafter, flasks were closed and kept closed carefully. Applied samples were incubated without connecting to the flow-through system. As no evolution of ${ }^{14} \mathrm{CO}_{2}$ or ${ }^{14} \mathrm{CH}_{4}$ was expected, samples were locked gastight until sampling.

\section{Treatment with test substance}

The required volume of stock solution of the test item was pipetted into the manure under simultaneous stirring using the pipette tip. The pipette tip was left in the manure sample after application to avoid any losses since manure always sticks to the tip. Rinsing with water would have decreased the dry matter content of the sample and the tip is assessed to be inert.

$0.02 \mathrm{mg}{ }^{14} \mathrm{C}$-salicylic acid (75 kBq) plus $1.18 \mathrm{mg}$ unlabeled salicylic acid were dissolved in $3 \mathrm{~mL}$ ultrapure water containing $0.05 \%$ methanol and applied to $50 \mathrm{~g}$ manure fresh weight. For the test series using $300 \mathrm{mg}$ fresh weight manure, $0.12 \mathrm{mg}{ }^{14} \mathrm{C}$-salicylic acid plus $7.08 \mathrm{mg}$ unlabeled salicylic acid were used. Thus, the final concentration was $24 \mathrm{mg}$ salicylic acid/ $\mathrm{kg}$ manure fresh weight.

$0.004 \mathrm{mg}{ }^{14} \mathrm{C}$-paracetamol $(75 \mathrm{kBq})$ plus $1.196 \mathrm{mg}$ unlabeled paracetamol were dissolved in $5 \mathrm{~mL}$ ultrapure water containing $0.05 \%$ acetonitrile and applied to $50 \mathrm{~g}$ manure fresh weight. Thus, the final concentration was $24 \mathrm{mg}$ paracetamol $/ \mathrm{kg}$ manure fresh weight.

$0.02 \mathrm{mg}{ }^{14} \mathrm{C}$ "biocide B" (75 kBq) plus $0.03 \mathrm{mg}$ unlabeled "biocide B" were dissolved in $7 \mathrm{~mL}$ ultrapure water containing $0.05 \%$ acetonitrile and applied to $50 \mathrm{~g}$ manure fresh weight. Thus, the final concentration was $1 \mathrm{mg}$ biocide $\mathrm{B} / \mathrm{kg}$ manure fresh weight.

\section{Test duration and sampling}

Test duration depends on the rate of transformation of the parent compound and transformation products. Sufficient sampling time points were included to unambiguously derive all required (kinetic) parameters for parent substance and transformation products. Six replicate incubation vessels were sacrificed per sampling point. This was needed to obtain a reliable data base for statistical analyses.

In the first test series, which investigated the influence of the test system setup (amount of manure, flow-through vs semi-static conditions, flow rate) on the mineralization rate of ${ }^{14} \mathrm{C}$-salicylic acid, sampling of $\mathrm{NaOH}$ containing traps was at $3,7,14,29,35,42,49,56,63,70,79$ and 91 days after treatment (DAT) (cattle manure), and 3, 7, 14, 21, 29, 35, 42, 49, 56 and 63 DAT (pig manure).

In the second test series, which investigated the influence of manure of different type and origin on the transformation rate and route of ${ }^{14} \mathrm{C}$-salicylic acid, samples were incubated for 0 h, 3 days, 7 days, 14 days, 21 days, 28 days, and 35 days. Abiotic controls (sterile samples) were also incubated and taken at the end of the study. Samples treated with ${ }^{14} \mathrm{C}$-paracetamol were incubated for 0 h, 7 h, 1 day, 3 days, 7 days, 14 days, and 28 days (cattle manure and pig manure, BAY_2p). Pig manure samples from the sites NRW_1p and NRW_2p were incubated for 0 h, 1 day, 3 days, 7 days, 14 days, 28 days, and 41 days. Abiotic controls were sampled at the end of the study that was at $28 \mathrm{DAT}$ and $41 \mathrm{DAT}$, respectively. Manure samples spiked with "biocide B" were incubated for $0 \mathrm{~h}$, 7 days, 21 days, 42 days, 63 days, 84 days, and 105 days. Abiotic controls were sampled at 86 DAT.

\section{Clean-up of manure samples}

At sampling, the manure subsamples were sacrificed by removing the vessels from the incubation system and cleaned-up directly after sampling without storage. Extraction was done by the use of appropriate solvents (e.g. methanol, acetonitrile) depending on the properties of the test substance. For details on the extraction procedure, see Hennecke et al. [15]. The extraction was achieved by the addition of a sub-portion of the first extraction solvent to the incubation vessel, gently shaking the mixture and transferring it into a centrifuge tube. This procedure was repeated until the complete manure was removed from the incubation vessel. The manuresolvent mixture was shaken for $30 \mathrm{~min}$. Thereafter, the mixture was centrifuged for $10 \mathrm{~min}$ at $739 \times g$. The supernatant, i.e. the first extract, was collected. Further extraction solvent was added to the pellet. The whole process was repeated twice. Extracts 1-3 were combined, counted for their radioactivity content (by liquid scintillation counting of an aliquot) and subjected to substance-specific analysis; in this case, thin-layer chromatography with radio-detection and co-chromatography of the labeled parent compound.

The residual solvent was allowed to evaporate from the manure pellet at room temperature. Aliquots were quantified by combustion and radio-assaying the evolved ${ }^{14} \mathrm{CO}_{2}$. In case non-extractable residues (NER) exceeding $10 \% \mathrm{aR}$ are observed, further extraction methods should be applied additionally. These methods comprise, e.g. pressurized liquid extraction (e.g. ASE ${ }^{\circledR}$ ), reflux, soxhlet, etc. with appropriate solvents. Usually, these solvents are identical to those used in the first extraction steps. According to experiments performed prior to the main 
tests, it is advisable to apply the harsh extraction twice in order to exhaustively extract the residues. In case the amount of radioactivity exceeds $5 \%$ aR the extract should be subjected to substance-specific analysis. However, in the course of the research project, ASE $^{\circledR}$ was applied occasionally only to check the potency of the extraction procedure. Residues remaining after the last extraction step (non-extractable residues, NER) were quantified by combustion and radio-assaying the evolved ${ }^{14} \mathrm{CO}_{2}$.

\section{Establishment of mass balance}

A mass balance was determined and calculated for each sampling interval. This was done by radio-counting the phases and summing up the amount of radioactivity given in (\% of applied radioactivity; $\%$ aR) in the aqueous/organic extracts plus $\mathrm{ASE}^{\circledR}$ plus volatiles other than ${ }^{14} \mathrm{CO}_{2}$ plus ${ }^{14} \mathrm{CO}_{2}$ and ${ }^{14} \mathrm{CH}_{4}$ plus non-extractable residues (NER).

\section{Calculation of half-lives}

In the first test series on the influence of the test system setup on the mineralization rate of ${ }^{14} \mathrm{C}$-salicylic acid, mineralization half-lives (expressed as $\mathrm{DT}_{50}$ MIN values, i.e. values for the time needed for the formation of half of maximum theoretically achievable ${ }^{14} \mathrm{CO}_{2}$ plus ${ }^{14} \mathrm{CH}_{4}$ ) were calculated by means of the KinGUI software tool [27] and using the SFO (Single First Order) kinetic model.

In the second test series, compounds were analyzed based on the recommendation of the Forum for the Co-ordination of pesticide fate models and their Use (FOCUS) work group on degradation kinetics [28]. In addition to the SFO kinetic model, HS (Hockey stick), DFOP (Double first order in parallel), and FOMC (Firstorder multi-compartment) kinetics were used to calculate the time needed for disappearance of $50 \%\left(\mathrm{DT}_{50}\right.$ value) and $90 \%\left(\mathrm{DT}_{90}\right.$ value) of the parent and transformation products, if appropriate, by means of the KinGUI-software tool [27]. $\chi^{2}$ values were used to evaluate the goodness of fit for all different kinetic models and a visual check of the graphs of all models was performed. According to FOCUS [26], $\chi^{2}$ values $<15 \%$ indicate that the respective model is well suited to explain the observed data.

\section{Statistical analyses}

Statistical analysis was performed by calculating arithmetic means including standard deviation and coefficient of variation $(\mathrm{COV})$. In addition, testing on homogeneity of variances (Levene's test [29]; $\alpha=5 \%$ ) and testing on equal central moments (Mann-Whitney $U$ test; $\alpha=5 \%$ ) were performed to test the influence of storage conditions (temperature and duration of storage in the laboratory) and duration of manure acclimation period on microbial activity of manure, as well as the variability of manure matrix parameters, and the influence of the origin of manure on substance transformation.

\section{Results and discussion}

\section{Spatial and seasonal variability of manure parameters}

Figure 1 presents an overview on the variability of each manure parameter. Individual values can be found in Additional file 1: Table S4 (cattle manure, winter), Table S5 (cattle manure, summer) and Table S6 (pig manure).

Arithmetic mean values of the dry matter content in cattle manure sampled in winter and summer, respectively, is $9.2 \%$ (coefficient of variation, COV 23\%) and $10.6 \%$ (COV 20\%). In pig manure, the mean is $5.2 \%$ (COV $60 \%$ ). The measured mean values are in-line with the EMA guidance document on determining the fate of veterinary medicinal products in manure [7]. Therein, a dry matter content of $10 \% \pm 1 \%$ and $5 \% \pm 1 \%$ for cattle and pig manure to be used for testing purposes is laid down (cf. paragraph 2.3.3).

The mean organic carbon content is $3.9 \% \mathrm{fw}$ (cattle, winter), $4.3 \% \mathrm{fw}$ (cattle, summer) and $2.1 \% \mathrm{fw}$ (pig). Corresponding COVs are $22 \%, 20 \%$ and $63 \%$, respectively. The determination of $\mathrm{NH}_{4}-\mathrm{N}$ resulted in means of $2020 \mathrm{mg} / \mathrm{kg} \mathrm{fw}$ (cattle, winter), $2100 \mathrm{mg} / \mathrm{kg} \mathrm{fw}$ (cattle, summer), and $2650 \mathrm{mg} / \mathrm{kg} \mathrm{fw}$ (pig); COVs are $25 \%, 19 \%$ and $38 \%$, respectively. Furthermore, total nitrogen content was measured and gave amounts of $4070 \mathrm{mg} / \mathrm{kg} \mathrm{fw}$ (cattle, winter), $4400 \mathrm{mg} / \mathrm{kg} \mathrm{fw}$ (cattle, summer) and 3750 $\mathrm{mg} / \mathrm{kg} \mathrm{fw}$ (pig) with COVs of $21 \%, 19 \%$ and $35 \%$, respectively. For cattle manure sampled in winter 2010/2011, the mean value for the temperature measured in the below ground manure storage tanks is $6.1^{\circ} \mathrm{C}(\mathrm{COV} 61 \%)$. For cattle manure sampled in summer, the mean temperature is $15.0^{\circ} \mathrm{C}$ ( $\left.\mathrm{COV} 15 \%\right)$, and for pig manure, it is $11.3^{\circ} \mathrm{C}(\mathrm{COV} 35 \%)$.

The COVs can be seen as a measure to describe the influence of regional and temporal conditions on manure parameters: the lower the COV, the lower the influence is. COVs of cattle manure parameters sampled in winter are in the range of $21-25 \%$ whereas values of cattle manure sampled in summer are in the range of $19-20 \%$. Generally spoken, COVs are relatively low indicating weak influences of regional conditions. Although these influences are slightly higher in winter, the differences are supposed to represent the natural variability of manure parameters. COVs of pig manure parameters are higher than those of cattle manure and range between 35 and $63 \%$. Thus, influences of regional conditions are more pronounced in pig manure. This might be explained by the pig manure texture, which is more heterogeneous and contains more extraneous materials (e.g. litter, feed, 

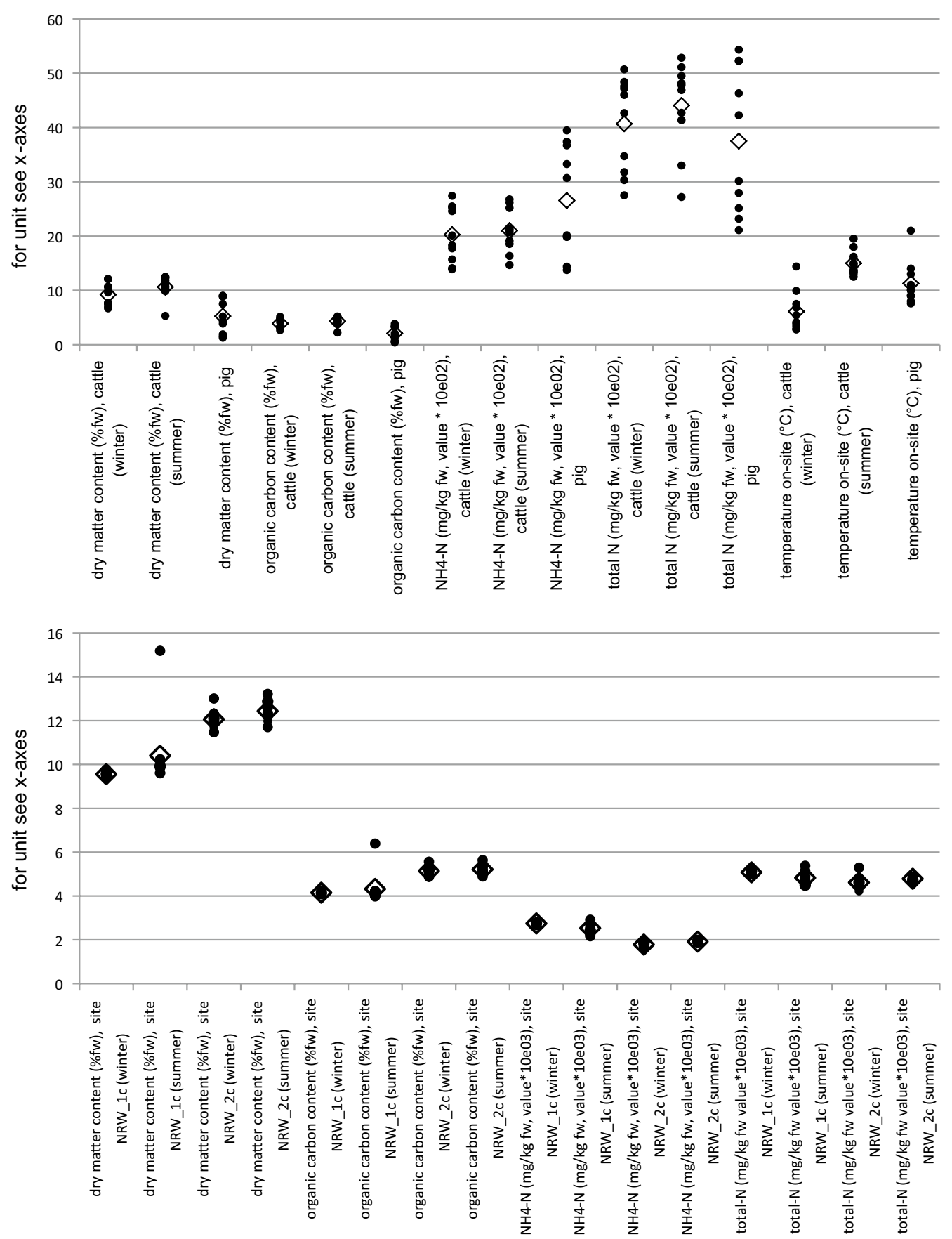

Fig. 1 Variability of samples from 10 sites (above) and variability of subsamples from 2 sites (below). Above: Single values (10 different manure samples per parameter; dots) as well as arithmetic means (open squares) for cattle manure sampled in winter 2010/2011, cattle manure sampled in summer 2011, and pig manure sampled in the period November 2011 to September 2012. Please notice the $y$-axes for $\mathrm{NH}_{4}-\mathrm{N}$ and total $\mathrm{N}$ are (value * 10E002). Below: Single values (10 replicates per site and parameter; dots) as well as arithmetic means (open squares). Please notice the y-axes for $\mathrm{NH}_{4}-\mathrm{N}$ and total- $\mathrm{N}$ are (value * 10E002)

larvae). Furthermore, arithmetic mean values of pig manure parameters are lower in all cases compared to those obtained for cattle manure. This indicates significant species-dependent differences. These conclusions are in line with the EMA guidance document on determining the fate of veterinary medicinal products in manure [7] where it is stated that "for pragmatic reasons, manure within the same animal species, i.e. pigs, 
cattle and poultry is considered to be comparable". Thus, extrapolation of transformation study results from one species to another is not possible. Testing of each target species is needed.

\section{Homogeneity of sampling}

The homogeneity of the described sampling procedure was investigated by evaluation of 10 replicates of cattle manure sampled at two sites, both in winter and in summer $(n=40)$. Table 4 gives an overview on means, standard deviation and COV for all analyzed parameters (individual data for replicates are available in Additional file 1: Tables S7-S10).

$\mathrm{COV}$ for all parameters of 10 replicates sampled in winter at sampling site NRW_1c are very low (1.1-1.5\%). For that sampling site, variation is higher for manure sampled in summer (COV 6.2-17.0\%), which indicates a more heterogeneous distribution of summer manure within the storage tank compared to winter manure. In contrast, variations between the 10 replicates sampled at site NRW_2c are somewhat higher compared to winter manure at site NRW_1c. On the other side, differences in COVs between winter manure $(3.5-6.2 \%$,) and summer manure $(1.8-4.1 \%)$ at site NRW_2c are low. This indicates an even distribution of manure in the storage tank both, for manure sampled in summer and in winter.

Overall, COV regarding manure parameters between 10 replicates of sampling are low. Therefore, it can be concluded that the sampling methodology described in "Methods" section yields homogeneous manure samples, and thus is a suitable procedure to sample manure for testing purposes. In contrast, variation of parameters for cattle manure samples from different regional origin is consistently much higher in both summer and winter (COV range 19-25\%; cf. Additional file 1: Tables S4 and S5) compared to samples taken from the same manure tank (COV range 1.2-17.0\% NRW_1c; 1.8-6.2\%, NRW_2c, Table 4). In summary, a practicable and reproducible method to collect homogenous manure samples could be established, which is a major achievement and a prerequisite for conducting reproducible transformation studies.

\section{Influence of storage duration and temperature} in the laboratory on microbial activity of manure

Once the manure has been collected from the storage tank, it is transferred to the laboratory where further storage might be necessary until the manure is used for a transformation study. The influences of storage duration and temperature on the microbial activity of the manure were examined as described in "Methods" section on "storage of manure". When using fresh manure (directly after collection from the manure tank plus an acclimation period of 21 days), ${ }^{14} \mathrm{C}$-glucose mineralization ranged between 63 and 70.5\%. It increased to $93 \%$ and 105\% after 28 days storage at $4{ }^{\circ} \mathrm{C}$ and $20{ }^{\circ} \mathrm{C}$, respectively. At longer storage periods, ${ }^{14} \mathrm{C}$-glucose mineralization rates again decreased to $47-88 \%$ (63 days storage; $4{ }^{\circ} \mathrm{C}, 20{ }^{\circ} \mathrm{C}$ ) and $42-58 \%\left(105\right.$ days storage; $\left.4{ }^{\circ} \mathrm{C}, 20^{\circ} \mathrm{C}\right)$ indicating a loss of microbial activity (see Additional file 1: Table S11

Table 4 Homogeneity of sampling: results for 10 replicates per sampling site

\begin{tabular}{|c|c|c|c|c|}
\hline Code sampling site & Dry matter (\%) & $\mathrm{NH}_{4}-\mathrm{N}(\mathrm{mg} / \mathrm{kg} \mathrm{fw})$ & Total nitrogen (mg/kg fw) & $\begin{array}{l}\text { Organic } \\
\text { carbon (\% } \\
\text { fw) }\end{array}$ \\
\hline \multicolumn{5}{|l|}{ NRW_1c winter } \\
\hline Mean & 9.6 & 2741 & 5071 & 4.1 \\
\hline SD & 0.1 & 34.2 & 78.3 & 0.1 \\
\hline $\operatorname{cov}(\%)$ & 1.2 & 1.3 & 1.5 & 1.2 \\
\hline \multicolumn{5}{|l|}{ NRW_1c summer } \\
\hline Mean & 10.4 & 2529 & 4822 & 4.3 \\
\hline SD & 1.7 & 258.2 & 300.0 & 0.7 \\
\hline $\operatorname{cov}(\%)$ & 16.3 & 10.2 & 6.2 & 17.0 \\
\hline \multicolumn{5}{|l|}{ NRW_2c winter } \\
\hline Mean & 12.1 & 1775 & 4607 & 5.1 \\
\hline SD & 0.4 & 79.9 & 284.1 & 0.2 \\
\hline $\operatorname{cov}(\%)$ & 3.5 & 4.5 & 6.2 & 3.7 \\
\hline \multicolumn{5}{|l|}{ NRW_2c summer } \\
\hline Mean & 12.4 & 1915 & 4778 & 5.2 \\
\hline SD & 0.4 & 37.1 & 85.2 & 0.2 \\
\hline $\operatorname{cov}(\%)$ & 3.6 & 1.9 & 1.8 & 4.1 \\
\hline
\end{tabular}


for individual mineralization rates; values presented in the text are mean values). Based on the results, it is recommended to store manure not longer than 2 months under anaerobic conditions in the lab before testing. The experiments further showed that an influence of the storage temperature on the results cannot be excluded. In general, mineralization at $20{ }^{\circ} \mathrm{C}$ was higher than at $4{ }^{\circ} \mathrm{C}$. Beyond that, variability between replicates was higher at a storage temperature of $4{ }^{\circ} \mathrm{C}$ compared to $20^{\circ} \mathrm{C}$. Therefore, it is recommended that manure should be stored in the laboratory preferably at test temperature.

\section{Influence of duration of manure acclimation period on microbial activity of manure}

${ }^{14} \mathrm{C}$-glucose mineralization rates for acclimation periods of 3 days and 21 days are different. A longer acclimation period seems to improve microbial activity. Independent from storage temperature, a mean mineralization rate of $43.0 \% \pm 10.8 \%$ is observed after a 3-day acclimation period. After 21 days of acclimation, the mean mineralization rate amounts to $64.9 \% \pm 8.8 \%$ (see Additional file 1: Table S12 for individual mineralization rates). Furthermore, variability of the results was lower after 21 days of acclimation (COV 13.5\%) compared to 3 days of acclimation (COV 25.2\%).

The acclimation period (and the previous storage conditions) should help to obtain reproducible results under conditions as realistic as possible taking into account several factors: the results of different experiments should be comparable (e.g. matrix heterogeneity should be reduced during storage/acclimation by transformation of readily degradable organic constituents); anaerobic conditions should be established after sampling; different storage conditions (e.g. duration and temperatures) prior to acclimation should be balanced; the manure should show a sufficient microbial activity to have the potential for biodegradation of the test substance.

Thus, it is recommended to have an acclimation period of $21( \pm 1)$ days in order to ensure a viable biological system simulating the conditions in an anaerobic liquid manure storage tank.

\section{Influence of incubation system design on mineralization rates of ${ }^{14} \mathrm{C}$-salicylic acid in cattle and pig manure (test series 1) \\ Flow-through vs semi-static conditions}

Figure 2 shows the formation of ${ }^{14} \mathrm{CO}_{2}$ plus ${ }^{14} \mathrm{CH}_{4}$ by transformation of ${ }^{14} \mathrm{C}$-salicylic acid in cattle and pig manure incubated in the flow-through and the semistatic system for 6 replicates which were run in parallel.

A visual check of the graphs indicates lower mineralization rates in the semi-static systems for both cattle and pig manure. This is confirmed by $\mathrm{DT}_{50 \mathrm{MIN}}$ values (see Additional file 1: Table S13 for details): Medians are 32.2 days (flow-through) and 41.5 days (semi-static), respectively, measured in cattle manure, and 19.0 days (flow-through) and 23.6 days (semi-static) in pig manure. Lower mineralization rates in the semi-static system might be attributed to incomplete ${ }^{14} \mathrm{CO}_{2}$ and ${ }^{14} \mathrm{CH}_{4}$ purging at samplings other than the last one. At the last sampling, the manure subsamples were further treated by addition of $10 \mathrm{~mL} 10 \% \mathrm{HCl}$ to completely strip potentially dissolved $\mathrm{CO}_{2}$. Mass balances at the end of the study are in the range of $89.7 \%$ aR to $96.4 \%$ aR (data not presented in this paper).

Thus, a recommendation for a suitable test setup depends on the test substance properties such as volatility and anticipated mineralization rate: a semi-static test design should be used as it mimics the situation in a manure storage tank, and-from an experimentally point of view-losses of volatile transformation products including $\mathrm{CO}_{2}$ are mostly avoided. A flow-through design might also be used for substances which show no or only low mineralization. These recommendations are supported by the results of test series 2 as presented below, and are furthermore in agreement with conclusions, which have been drawn from the ring test results [14].

\section{Flow rate}

$\mathrm{DT}_{50}$ MIN values for the transformation of ${ }^{14} \mathrm{C}$-salicylic acid incubated under slow flow and fast flow conditions (flow-through system) are comparable (cf. Additional file 1: Table S13 for detailed data). This is observed for both types of manure. Medians of $\mathrm{DT}_{50 \mathrm{MIN}}$ values are 47.5 days (slow flow) and 50.2 days (fast flow), respectively, measured in cattle manure, and 14.6 days (slow flow) and 14.2 days (fast flow) in pig manure. Recoveries at the end of the incubation period are found to be in the range of 89.0 to $105.0 \%$ aR (data not presented in this paper). Thus, the flow rate does not influence the results of the transformation study and can be selected according to system's needs.

\section{Amount of incubated manure (50 g vs $300 \mathrm{~g}$, flow-through system)}

Lower mineralization rates for both types of manure are observed in case $300 \mathrm{~g}$ manure is used.

Observed $\mathrm{DT}_{50}$ MIN values (medians) are 47.5 days $(50 \mathrm{~g})$ and 62.4 days (300 g) measured in cattle manure, and 14.6 days (50 g) and 26.5 days (300 g) in pig manure (see Additional file 1: Table S13 for details). Mass balances at the end of the study are in the range of $82.2 \%$ aR to $98.2 \%$ aR (data not presented in this paper).

Based on the available information, one possible explanation could be that it is more difficult to strip out all potentially dissolved ${ }^{14} \mathrm{CO}_{2}$ when using higher amounts 

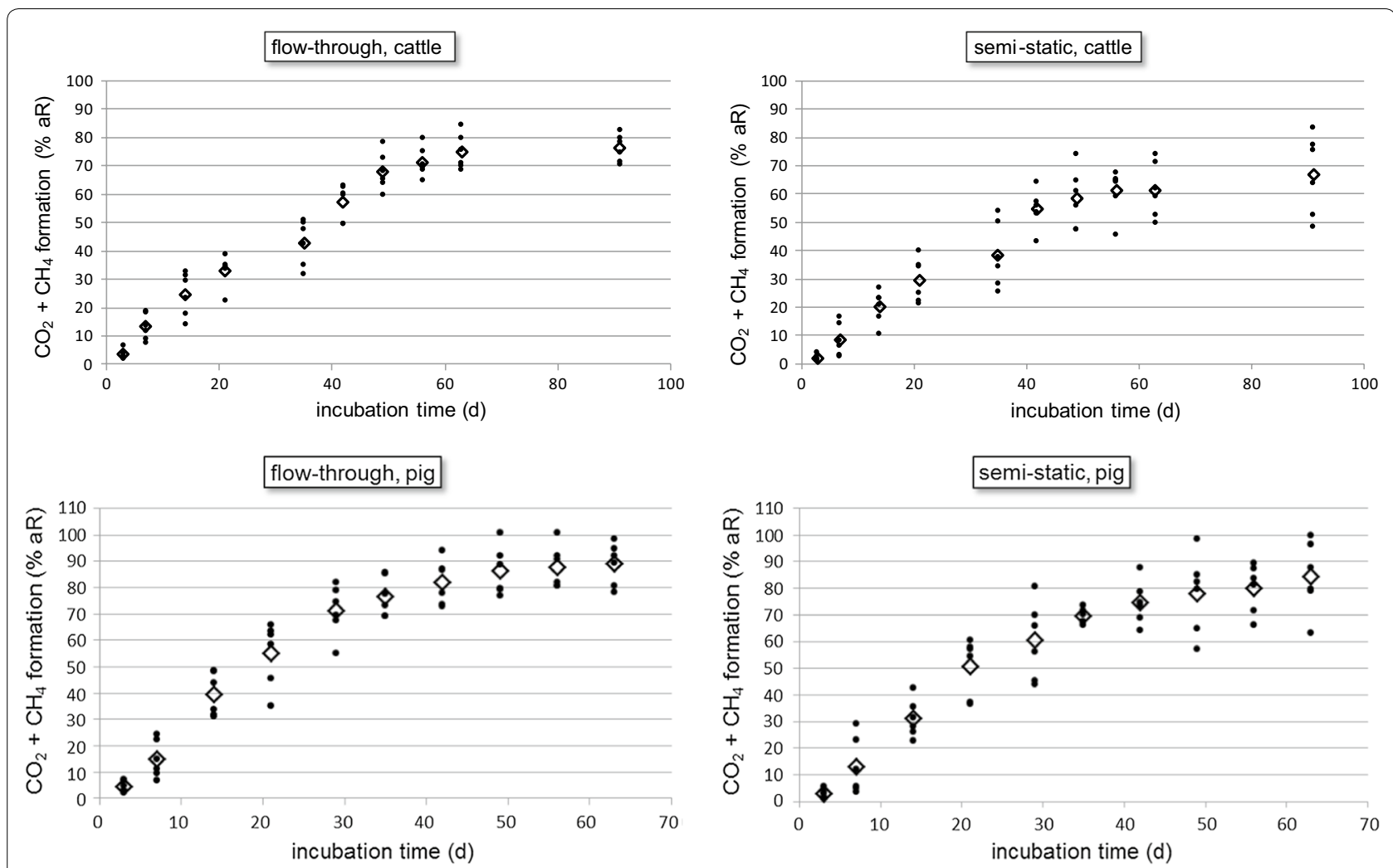

Fig. 2 Formation of ${ }^{14} \mathrm{CO}_{2}$ plus ${ }^{14} \mathrm{CH}_{4}\left(\%\right.$ aR) by transformation of ${ }^{14} \mathrm{C}$-salicylic acid. $50 \mathrm{~g}$ cattle and pig manure were incubated in the flow-through system (constant stream of nitrogen at 50-200 mL/min) and the semi-static system (intermittent stream of nitrogen). Results for 6 replicates per sampling (dots) and mean values (open squares) are given

of manure (i.e. a longer time period and/or additional bubbling with nitrogen might be necessary to strip out ${ }^{14} \mathrm{CO}_{2}$ ). While an amount of $300 \mathrm{~g}$ manure might be more representative for the conditions in a manure storage tank, $50 \mathrm{~g}$ manure subsamples are more easily to be handled in routine laboratory practice. This also reduces the amount of expensive ${ }^{14} \mathrm{C}$-radiolabeled test substance and saves organic solvent needed for extraction compared to a $300 \mathrm{~g}$ subsample weight.

\section{Summarizing remarks}

Regardless of the modifications of the study design, transformation of ${ }^{14} \mathrm{C}$-salicylic acid is faster in pig manure compared to cattle manure. One potential reason might be the faster distribution of the test substance in pig manure due to the lower viscosity. However, other reasons (e.g. species-specific differences on microbial community level) cannot be ruled out. This emphasizes the need to test manure of each target species separately. As the test design might influence the results obtained in a transformation study guidance and recommendations are needed taking into account the conditions in a manure storage tank, feasibility considerations and substance properties. This is true for the amount of manure tested as well as the selection of a flow-through or semi-static test system. The flow rate does not influence the test results.

\section{Studies on transformation of ${ }^{14} \mathrm{C}$-salicylic acid, ${ }^{14} \mathrm{C}$-paracetamol and ${ }^{14} \mathrm{C}$-“biocide $\mathrm{B}$ " in cattle and pig manure of different origin (test series 2 )}

Besides radioactivity distribution and mass balances, the disappearance time for $50 \%\left(\mathrm{DT}_{50}\right)$ of the parent compound was also determined in test series 2 .

\section{Extractable residues, NER, mineralization and mass balance}

Figures 3, 4 and 5 present arithmetic mean values for total recoveries, extractable and non-extractable residues, and mineralization rates of the three substances over the entire test period for manure of both animal types. Mean values are calculated from three (six) experiments per animal type and six replicates per experiment. Mean values, standard deviation and COVs of the mentioned endpoints can be downloaded as Additional file 1: Tables S14 to S19. 

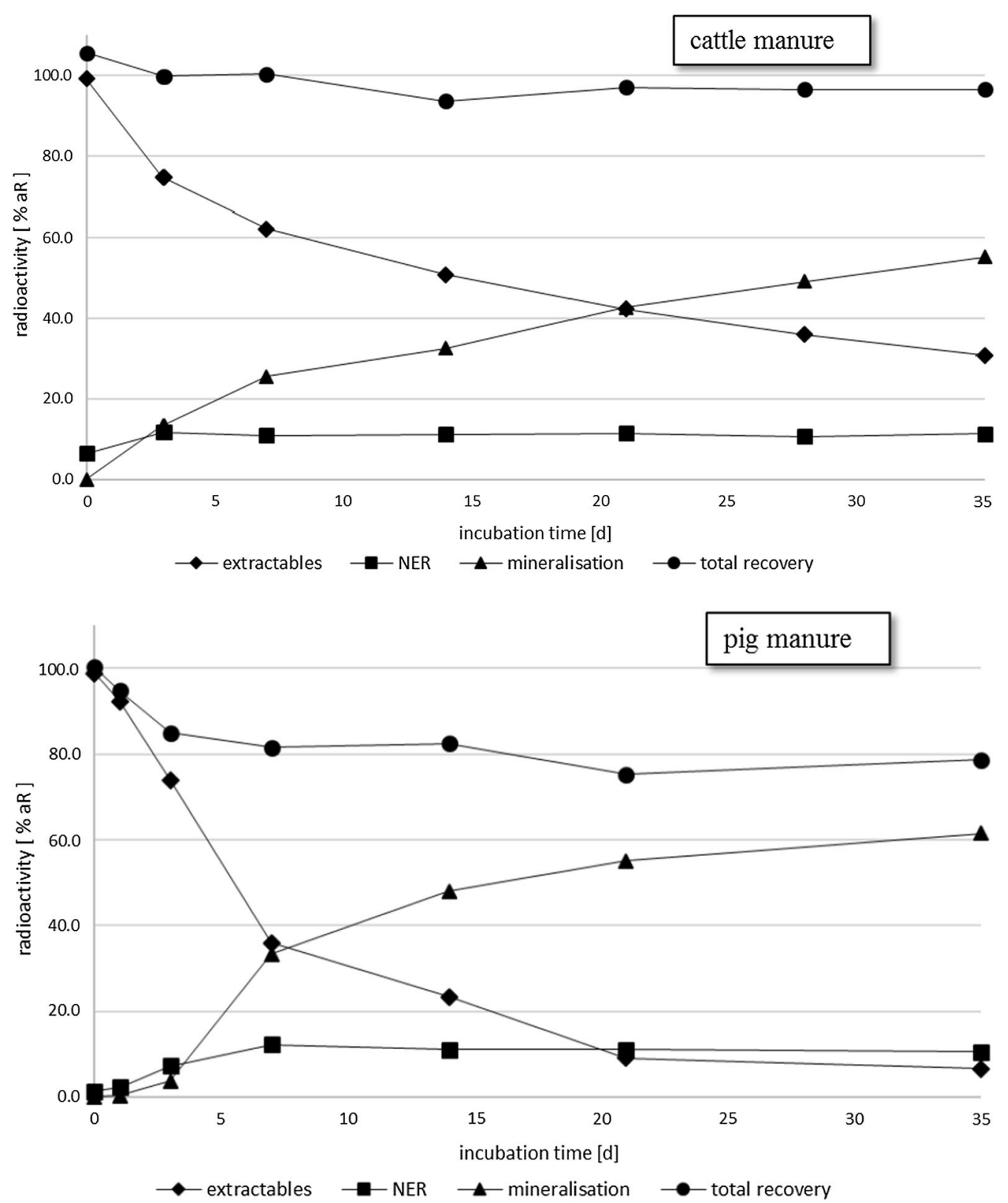

Fig. 3 Radioactivity distribution for transformation of ${ }^{14} \mathrm{C}$-salicylic acid in cattle (above) and pig (below) manure. Values are arithmetic mean values obtained from six experiments (cattle manure; three sites: NRW_1, NRW_2, BAY_1; sampling in winter and summer) and three experiments (pig manure; three sites: NRW_1, NRW_2, BAY_1) and six replicates per experiment. For standard deviation and COV, see Additional file 1:Tables S14 (cattle) and S15 (pig)

For ${ }^{14} \mathrm{C}$-salicylic acid (Fig. 3) tested in cattle and pig manure, the amount of extractable radioactivity significantly descends in the course of the incubation period and reaches $30.3 \pm 16.7 \%$ aR and $6.6 \pm 3.1 \%$ aR for cattle and pig manure, respectively. Formation of non-extractable residues is modest and amounts to $11.3 \pm 2.3 \%$ aR (cattle) and $10.5 \pm 2.4 \%$ aR (pig). Thus, NER formation is comparable for both animal species whereas the decrease in extractable residues is more pronounced in pig manure. The latter indicates a faster test substance transformation in pig manure.

This observation is also made for mineralization. At termination of the study, the amount of ${ }^{14} \mathrm{CO}_{2}+{ }^{14} \mathrm{CH}_{4}$ is $55.1 \pm 11.9 \%$ aR (cattle) and $61.6 \pm 4.8 \% \mathrm{aR}$ (pig), respectively. These high mineralization rates are accompanied by high coefficients of variation (COV), which are 

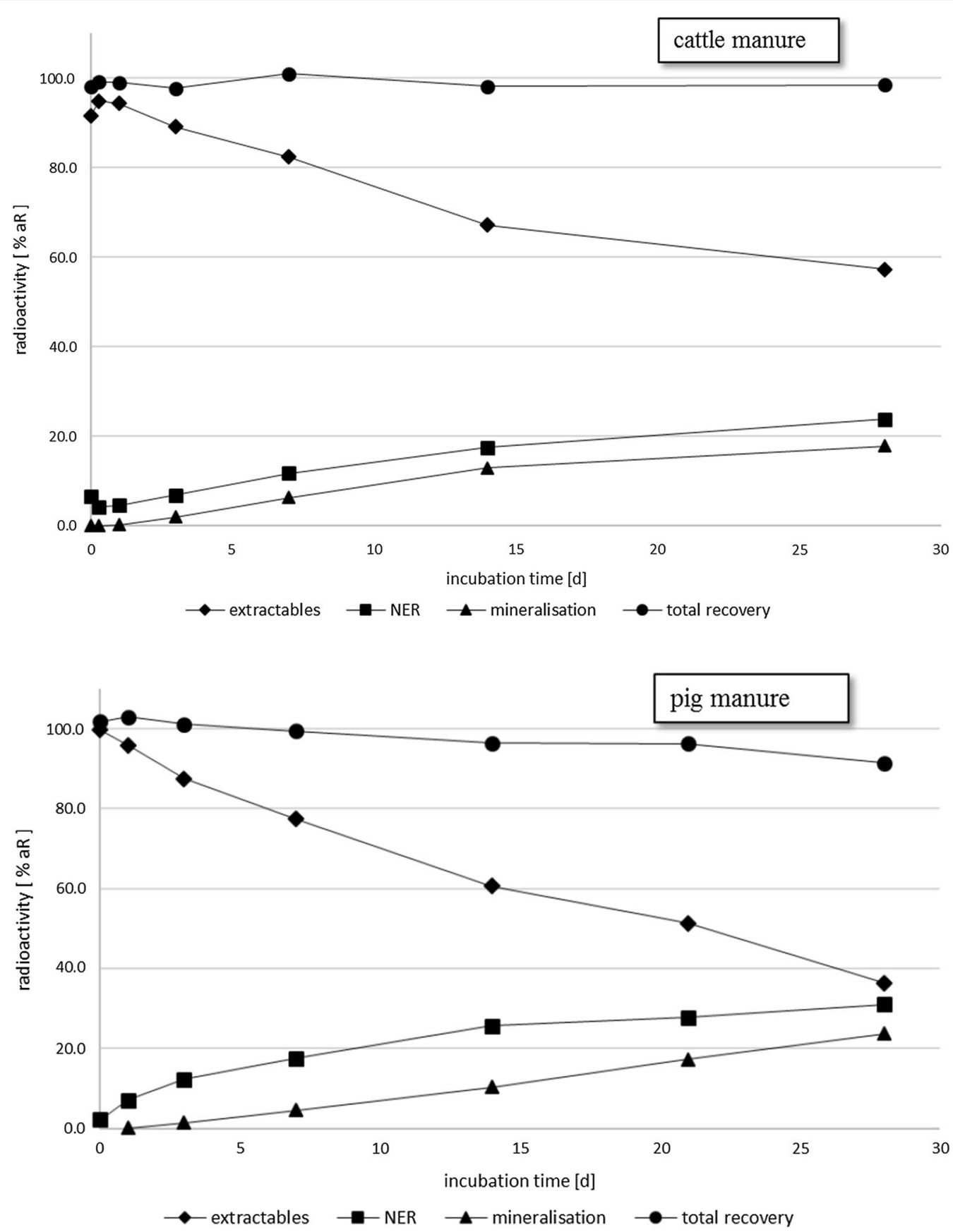

Fig. 4 Radioactivity distribution for transformation of ${ }^{14} \mathrm{C}$-paracetamol in cattle (above) and pig (below) manure. Values are arithmetic mean values obtained from three experiments for both animal types (three sites: NRW_1, NRW_2, BAY_1) and six replicates per experiment. For standard deviation and COV, see Additional file 1: Tables S16 (cattle) and S17 (pig)

in the range of $21.5-46.8 \%$ (cattle) and $7.8-72.0 \%$ (pig) throughout the studies. As the flow-through system was used, a periodical exchange of $\mathrm{NaOH}$-containing traps and thus opening of the incubation apparatus was necessary. Such operation might have resulted in losses of gaseous compounds in several of the subsamples, which led to variations of trapped ${ }^{14} \mathrm{CO}_{2}$ and ${ }^{14} \mathrm{CH}_{4}$. This can be avoided by the use of a semi-static system, which is strongly recommended in case of expected high mineralization rates. The selection of an appropriate incubation system depending on substance properties has been discussed above under the aspect of an influence of test 

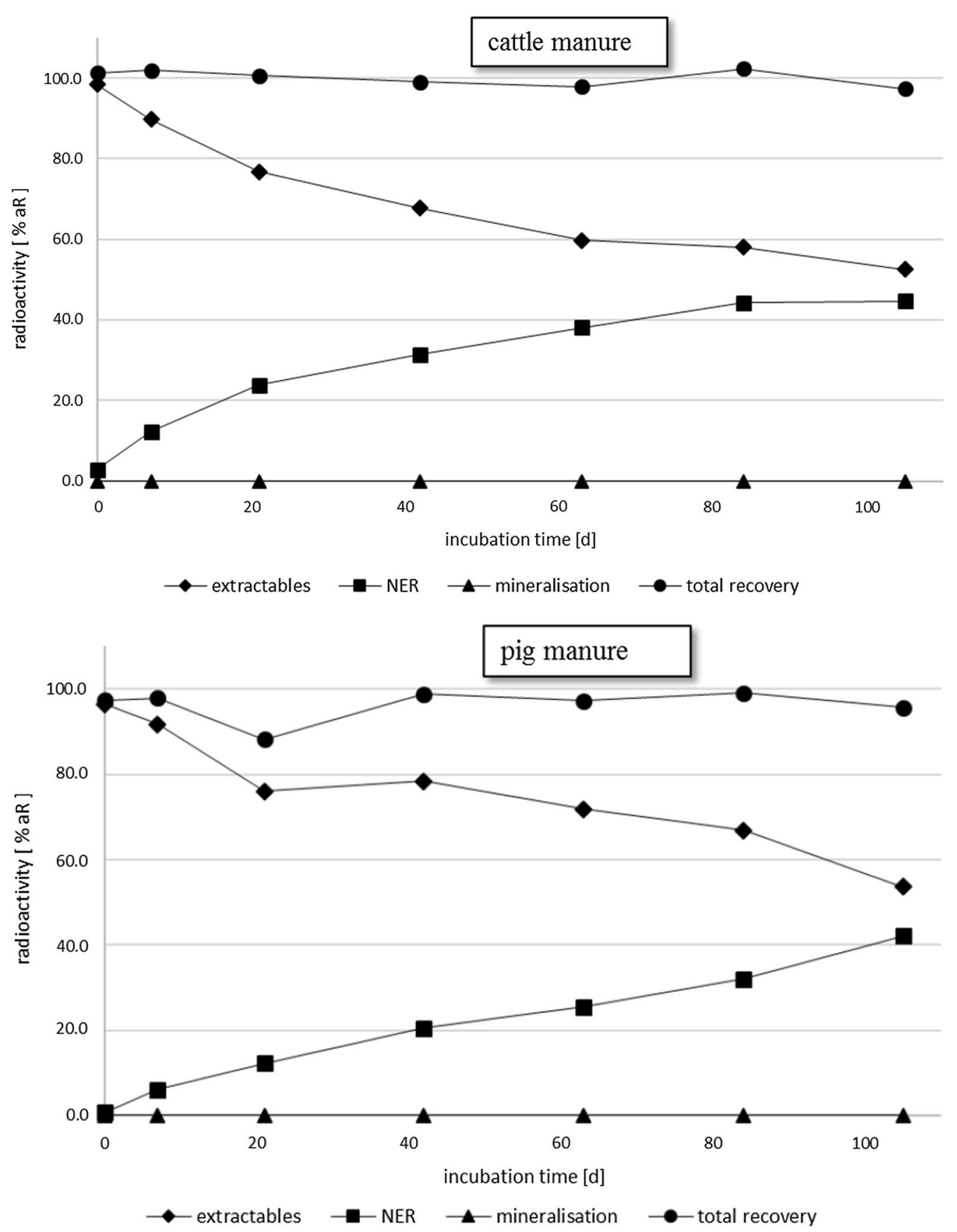

Fig. 5 Radioactivity distribution for transformation of ${ }^{14} \mathrm{C}$-biocide B in cattle (above) and pig (below) manure. Values are arithmetic mean values obtained from three experiments for both animal types (three sites: NRW_1, NRW_2, BAY_1) and six replicates per experiment. For standard deviation and COV see Additional file 1:Table S18 (cattle) and Additional file 1: Table S19 (pig)

design on the results of transformation studies. Similar experiences were made by the participants of the ring test [14]. This led to the respective recommendations on an appropriate test design as laid down in the suggested test method on transformation of VMPs and biocides in liquid manure [14].
Mean values for total recoveries are in the range of 93.5-105.5\% aR (cattle) and 75.2-100.2\% aR (pig). COVs vary between 4.4 and $11.0 \%$ (cattle) and $4.9-12.6 \%$ (pig). Low total recoveries in pig manure are supposed to be attributed to losses of mineralization products as already discussed above. 
In transformation studies with ${ }^{14} \mathrm{C}$-paracetamol (Fig. 4), the amount of extractable radioactivity continuously decreases in the course of the incubation period to reach $57.3 \pm 5.0 \%$ aR (cattle) and $36.3 \pm 7.1 \%$ aR (pig) by the end of the experiments after 28 days. During this period, formation of NER steadily increases up to $23.8 \pm 4.9 \% \mathrm{aR}$ (cattle) and $31.1 \pm 4.4 \% \mathrm{aR}$ (pig). In parallel, an increase of mineralization products $\left({ }^{14} \mathrm{CO}_{2}+{ }^{14} \mathrm{CH}_{4}\right)$ is observed. The sum of ${ }^{14} \mathrm{CO}_{2}+{ }^{14} \mathrm{CH}_{4}$ is $17.9 \pm 1.5 \%$ aR (cattle) and $23.7 \pm 4.7 \%$ aR (pig) at the end of the test. Thus, mineralization and the decrease of extractable residues during the incubation period are more pronounced in the studies performed with pig manure.

Total recoveries range between 97.7 and $101.0 \%$ aR (cattle), and 91.4 to $103.0 \% \mathrm{aR}$ (pig).

The amount of extractable residues decreases in the course of the transformation study with ${ }^{14} \mathrm{C}$ biocide $\mathrm{B}$ (Fig. 5), and is $52.6 \pm 6.0 \%$ aR (cattle) and $53.6 \pm 5.3 \%$ aR (pig) after 105 days of incubation. Vice versa, the amount of non-extractable residues steadily increases up to $44.7 \pm 4.3 \%$ aR (cattle) and $42.1 \pm 5.4 \%$ aR (pig). No final mineralization is observed. Total recoveries range between 97.3 and $102.3 \%$ aR (cattle), and 88.3 to $99.1 \%$ aR (pig). Worth mentioning is the comparability of the substance behavior in manure of both animal types, which is different from the other test substances.

\section{Mass balance as quality criterion}

As a quality criterion in OECD test guidelines 307 [12] and OECD 308 [13], a mass balance/recovery in the range of $90-110 \%$ for labeled chemicals and of $70-110 \%$ for non-labeled chemicals is given. However, due to the more complex and heterogeneous matrix manure, a mass balance of $\geq 90 \%$ for ${ }^{14} \mathrm{C}$-labeled compounds might not be achievable in all cases. The range for labeled compounds was selected based on the results of this study and on frequency distributions of mass balances from ring test results with cattle and pig manure. $88-93 \%$ of ${ }^{14} \mathrm{C}$-mass balances were within $100 \pm 15 \%$ aR, whereas only $60-86 \%$ of mass balances were in the range $100 \pm 10 \%$ aR [14]. Consequently, a quality criterion of $100 \pm 15 \%$ $\mathrm{aR}$ for mass balance is proposed, taking into account the specifics of the manure matrix.

\section{Summarizing remarks}

Arithmetic mean values, SD and COVs have been determined based on the data on extractable residues, NER and mass balance from all experiments with manure from one animal species each but of different temporal and regional origin. A detailed overview on all results is shown in Additional file 1: Tables S14 to S19. It is worth noting that COVs for six replicates of one sampling site in comparison to COVs for mean values of all sites are within the same range for both cattle and pig manure. This implies that using manure from different origins lies within the variability for the test. Differences in the results between animal species (cattle or pig) were observed. These results support the EMA guidance [7] to test each target species of the veterinary pharmaceutical product.

\section{Kinetic evaluation of test substance dissipation ( $D T_{50}$ values)} Transformation of ${ }^{14} \mathrm{C}$-salicylic acid was studied in cattle manure sampled in winter and in summer as well as in pig manure sampled in March to June. For both types of manure, sampling was at three different sites named as NRW_1c, NRW_2c, and BAY_2c for cattle manure and NRW_1p, NRW_2p, and BAY_2p for pig manure. Six replicates per transformation study were analyzed, and results discussed herein are arithmetic means and standard deviation obtained for these replicates. Although in some cases $\chi^{2}$ values slightly above 15 were observed, the SFO model proved to yield the overall best fit based on $X^{2}$ values and visual assessment, compared to HS, FOMC and DFOP models. Therefore, all kinetic evaluations were performed using SFO kinetics.

Figure 6 shows mean $\mathrm{DT}_{50}$ values of parent for the transformation in cattle manure in the range of 3.6 days to 27.9 days. Standard deviations range between 0.1 and 10.3 days. Coefficients of variation are in the range of $3-46 \%$. Dissipation in pig manure is faster compared to that in cattle manure. The range of mean $\mathrm{DT}_{50}$ values of parent is 3.9-7.2 days. Standard deviations range between 0.3 and 0.8 days; coefficients of variation are between 7 and $11 \%$. The range of standard deviation and coefficients of variation are narrower for pig manure compared to cattle manure. The detailed information on $\mathrm{DT}_{50}$-values for parent for all replicates, sampling sites in summer and in winter and both species are shown in Additional file 1: Tables S20 to S22.

Transformation of ${ }^{14} \mathrm{C}$-paracetamol was studied in cattle manure (sampled in July and August) and in pig manure (sampled in November, February and March). For both types of manure, sampling was at three different sites, namely NRW_1c, NRW_2c, and BAY_2c (for cattle manure) and NRW_1p, NRW_2p, and BAY_2p (for pig manure). Six replicates per transformation study were analyzed. $\mathrm{DT}_{50}$ values of parent for the transformation in cattle manure are in the range of 9.4-16.3 days. Standard deviations are between 1.1 and 1.4, coefficients of variation between 9 and $12 \%$. Means of $\mathrm{DT}_{50}$ values of parent obtained in pig manure are somewhat lower. They are in the range of 4.8-7.2 days. Standard deviations range between 0.5 and 1.6 days, coefficients of variation between 8 and 23\%. Individual $\mathrm{DT}_{50}$ values of parent and means are presented in Fig. 6. The detailed information 

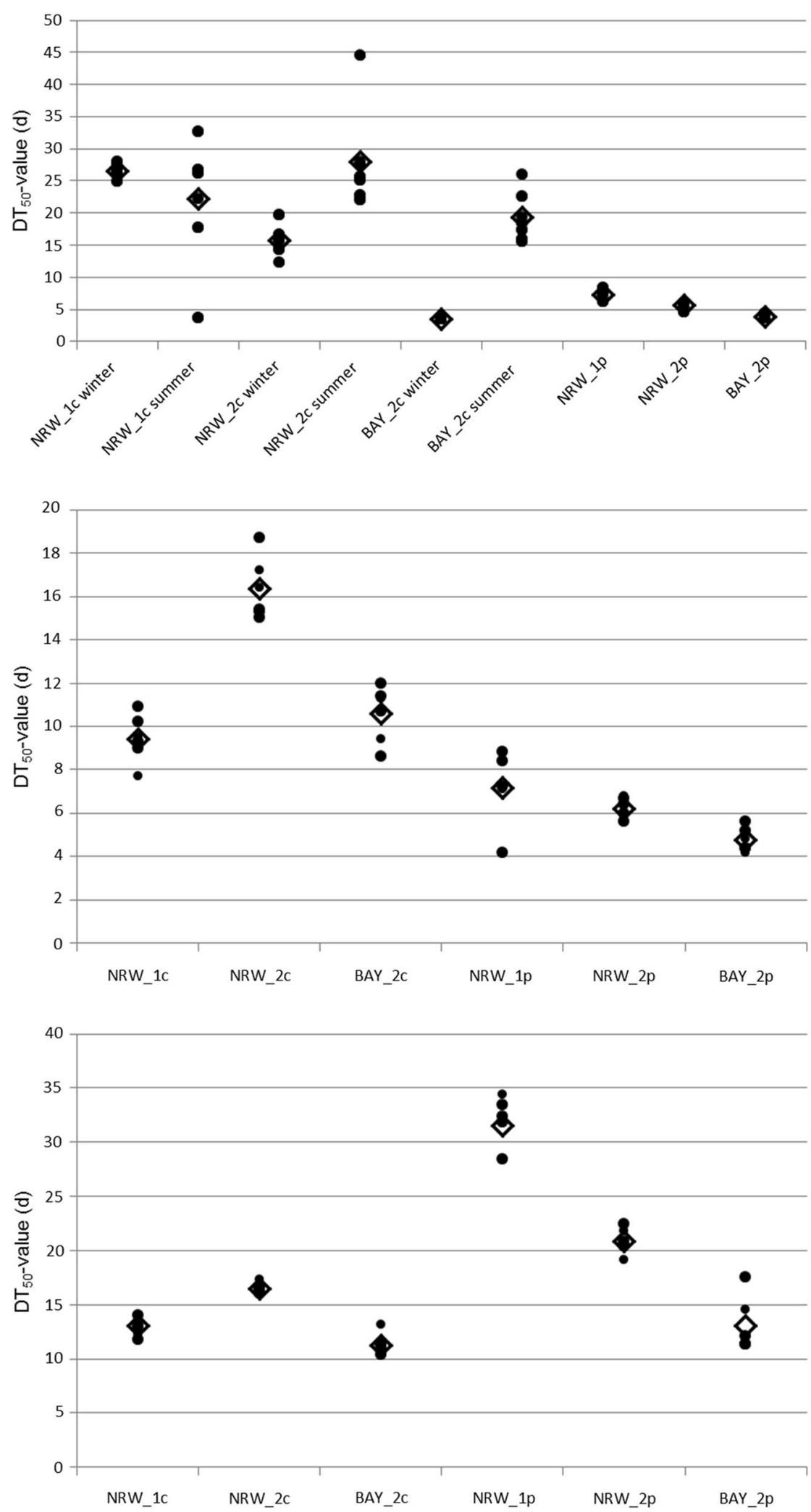

Fig. $6 D_{50}$ values for transformation of salicylic acid (above), paracetamol (middle) and biocide B (below). Transformation in cattle (index_c) and pig (index_p) manure of different origin. Results for 6 replicates per transformation study (dots) and mean values (open squares) are given 
on all individual $\mathrm{DT}_{50}$ values for parent are presented in Additional file 1: Tables S23 and S24.

Transformation of ${ }^{14} \mathrm{C}$-biocide $\mathrm{B}$ also was studied in cattle manure (sampled in July, August and November) and in pig manure (sampled in June and July). As for the other tested chemicals, sampling was at three different sites, NRW_1c, NRW_2c, and BAY_2c (for catthe manure) and NRW_1p, NRW_2p, and BAY_2p (for pig manure). Six replicates per transformation study were analyzed. $\mathrm{DT}_{50}$ values of parent for the transformation in cattle manure range between 11.3 and 16.5 days (cf. Fig. 6). Standard deviations are rather low and in the range of 0.5-1.0 days, whereas coefficients of variation are in range of $3-9 \%$. For the sites NRW_1p and $\mathrm{NRW} \_2 \mathrm{p}$, means of $\mathrm{DT}_{50}$ values obtained in pig manure are higher compared to cattle manure, and are 20.9 days and 31.5 days, respectively. The $\mathrm{DT}_{50}$ value of parent for the dissipation of ${ }^{14} \mathrm{C}$-biocide $\mathrm{B}$ in pig manure sampled at the site BAY_2p is 13.0 days. Again, standard deviations are rather low and between 1.2 and 2.5 days; coefficients of variation are in the range of $6-19 \%$. The detailed information on all individual $\mathrm{DT}_{50}$ values for parent is presented in Additional file 1: Tables S25 and S26.

\section{Conclusions}

The aim of this study was to establish a reliable experimental test method to examine the anaerobic transformation of veterinary pharmaceuticals and biocides in liquid cattle and pig manure. The influences of manure specifics and manure parameters on transformation rates, formation of extractable and non-extractable residues and mineralization addressed in this study are summarized below.

\section{Manure characterization, sampling and storage}

- Selection of sampling date and site Seasonal conditions do not influence manure parameters. Thus, manure for testing purposes can be collected at any time of the year.

- Sampling method from manure tank The here described method to sample manure directly from a storage tank by applying a homogenization step prior to sampling proved to yield in reproducible manure samples with similar manure matrix parameters, such as dry matter content (Table 4).

- Storage duration and temperature in the laboratory To avoid changes in microbial activity, if necessary, it is recommended to store manure no longer than for 2 months once it has been collected from the tank. Storage temperature influences the microbial activity. Thus, storage in the laboratory prior to use for a transformation study should preferably be at test temperature.

- Duration of manure acclimation period The length of the acclimation (or pre-incubation) period influences the microbial activity of manure and observed variability. It is recommended to use an acclimation period of $21 \pm 1$ days to ensure comparable testing conditions.

\section{Transformation studies \\ Influence of test setup on mineralization rates}

- It cannot be excluded that the regime of passing nitrogen over the samples (semi-static vs flowthrough systems) influences the results of a transformation study. Therefore, a semi-static system is preferred over a flow-through system as it rather represents the real conditions in a manure storage tank and can be handled more easily by laboratories. In particular, this is true for volatile test compounds and for substances with anticipated high mineralization rates. When using a semi-static setup, it particularly is of importance to acidify the samples to release trapped $\mathrm{CO}_{2}$ after sampling.

- The flow rate (flow-through system) does not influence the results of the transformation study.

- The amount of manure (50 g vs $300 \mathrm{~g}$ wet weight) used in a transformation study influences the results. To obtain comparable results from transformation studies, guidance on the amount of manure to be treated is needed. Though an amount of $300 \mathrm{~g}$ is more representative for the conditions in a manure storage tank, $50 \mathrm{~g}$ manure subsamples facilitate practical laboratory work.

\section{Influence of type and origin of manure on transformation rates}

- With regard to mass balance parameters, COVs for six replicates of one sampling site are within the same range as COVs for mean values of all sites, indicating that the influence of manure origin lies within the variability for the test.

- COVs for $\mathrm{DT}_{50}$ values are rather low for both cattle (mean 14.3\%; range 3-46\%) and pig (mean 11.3\%; range 6-23\%) manure. Thus, the obtained results can be considered as reproducible.

- It is necessary to test manure specifically from the species for which the VMP or biocide is used. A transfer of results from pig to cattle manure or vice versa is not possible. 


\section{Quality criteria}

- Based on the described experiments together with additional data from the ring test [14], the mass balance should range from 85 to $115 \%$ aR for radiolabeled test compounds and from 70 to $110 \%$ for non-labeled compounds.

- The test has to be conducted under anaerobic/ methanogenic conditions typically found in manure tanks [9]. As an indicator parameter, the measured redox potential (reported as $E_{h}$ ) should be $\leq-100 \mathrm{mV}$ throughout the entire test period.

The precise and reproducible results obtained in the presented study give a reliable basis for an experimental test method to perform transformation studies in anaerobic liquid manure. The presented work was used as guidance for an international ring test to validate the method and to work toward standardization of testing the transformation of chemicals in anaerobic liquid manure [14].

\section{Supplementary information}

Supplementary information accompanies this paper at https://doi. org/10.1186/s12302-020-00323-8.

Additional file 1. Additional data.

\begin{abstract}
Abbreviations
$\%$ aR: \% of applied radioactivity; ASE $^{\circledR}$ : Accelerated solvent extraction; Bq Bequerel; COV: Coefficient of variation; DAT: Days after treatment; DFOP: Double first order in parallel; $\mathrm{DT}_{50}$ value: Time needed for dissipation of $50 \%$ of the initial amount of a compound; DT 50 mIN: Time needed for formation of $50 \%$ of expected $\mathrm{CO}_{2}+\mathrm{CH}_{4}$ (mineralization); EMA: European Medicines Agency; FOCUS: FOrum for the Co-ordination of pesticide fate models and their Use; FOMC: First-order multi-compartment; fw: Fresh weight; HS: Hockey stick; NER: Non-extractable residues; OECD: Organisation for economic co-operation and development; SFO: Single first order; VFA: Volatile fatty acids; VMP: Veterinary medicinal product
\end{abstract}

\section{Acknowledgements}

We thank the following persons and institutions for their contributions to the development and experimental validation of the test protocol: Claudia Bickert, Udo Hommen, Michael Klein at Fraunhofer Institut für Molekularbiologie und Angewandte Ökologie (IME), Germany, Elena Heusner and Thomas Knacker at ECT Oekotoxikologie GmbH, Germany, Maria Meinerling at IBACON GmbH, Germany, Silke Fiebig at Noack Laboratorien GmbH, Germany, Sören ThieleBruhn at the University Trier, Soil Science Department, Faculty VI, Germany, Wolfgang Völkel at Innovative Environmental Services (IES) Ltd., Switzerland, Ed Topp at Agriculture and Agri-Food Canada (AAFC), Canada.

\section{Disclaimer}

The opinions and views expressed in this manuscript do not necessarily reflect those of the German Environment Agency.

\section{Authors' contributions}

$\mathrm{DH}, \mathrm{CA}, \mathrm{MH}, \mathrm{UMB}, \mathrm{TJ}$ and KHW elaborated the experimental setup and performed the experiments. $\mathrm{DH}, \mathrm{MH}, \mathrm{TJ}, \mathrm{JR}, \mathrm{RAD}, \mathrm{SB}$ and SK drafted the test method. MH, TJ and JW drafted the manuscript. SK and SB reviewed the manuscript. All authors read and approved the final manuscript.

\section{Funding}

The authors would like to thank the German Ministry for the Environment, Nature Conservation, and Nuclear Safety for financially supporting the present work under Grant Numbers FKZ 371067422 (Development of a test protocol to study the transformation of veterinary pharmaceuticals and biocides in liquid manure), and FKZ 371265420 (Harmonization of experimental exposure assessment for veterinary pharmaceuticals and biocides).

\section{Availability of data and materials}

All data necessary to interpret and replicate the findings reported are included in this published article and its supplemental data files. Further data used and/ or analyzed during the current study are available from the corresponding author on reasonable request.

\section{Ethics approval and consent to participate}

Not applicable.

\section{Consent for publication}

Not applicable.

\section{Competing interests}

The authors declare that they have no competing interests.

\section{Author details}

${ }^{1}$ ECT Oekotoxikologie GmbH, 65439 Flörsheim, Germany. ${ }^{2}$ Fraunhofer Institute for Molecular Biology and Applied Ecology IME, 57392 Schmallenberg, Germany. ${ }^{3}$ German Environment Agency, Unit IV 2.2 Pharmaceuticals and Nanomaterials, 06844 Dessau-Roßlau, Germany. ${ }^{4}$ Institute for Soil Science and Soil Conservation, Justus Liebig University, 35392 Giessen, Germany.

${ }^{5}$ Fraunhofer Institute for Environmental, Safety, and Energy Technology UMSICHT, 46047 Oberhausen, Germany.

Received: 1 October 2019 Accepted: 2 March 2020

Published online: 10 March 2020

\section{References}

1. Spielmeyer A (2018) Occurrence and fate of antibiotics in manure during manure treatments: a short review. Sustain Chem Pharm 9:76-86

2. Kreuzig R, Hartmann C, Teigeler J, Höltge A, Cvetković B, Schlag P (2010) Development of a novel concept for fate monitoring of biocides in liquid manure and manured soil taking ${ }^{14} \mathrm{C}$-imazalil as an example. Chemosphere 79:1089-1094

3. Nieman CC, Floate KD, Düring R-A, Heinrich AO, Young DK, Schaefer DM (2018) Eprinomectin from a sustained release formulation adversely affected dung breeding insects. PLOS ONE 13:e0201074

4. Gros M, Mas-Pla J, Boy-Roura M, Geli I, Domingo F, Petrović M (2019) Veterinary phartmaceuticals and antibiotics in manure and slurry and their fate in amended agricultural soils: findings from an experimental field site (Baix Empordà, NE Catalonia. Sci Total Environ 654:1337-1349

5. Thiele-Bruhn S (2019). Environmental risks from mixtures of antibiotic pharmaceuticals in soils_a literature review. UBA-Texte 32/2019. Umweltbundesamt, Dessau-Roßlau, Germany, p 120. https://www. umweltbundesamt.de/publikationen/environmental-risks-from-mixtu res-of-antibiotic

6. EMEA/CVMP (2008) Revised guideline on environmental impact assessment for veterinary medicinal products in support of the $\mathrm{VICH}$ guidelines GL6 and GL38. EMEA/CVMP/ERA/418282/2005-Rev.1. European Medicines Agency/Committee for Medicinal Products for Veterinary Use, London, UK

7. EMA (2011) "Guideline on determining the fate of veterinary medicinal products in manure" (EMA/CVMP/ERA/430327/2009 (revised in 2011))

8. Wohde M, Berkner S, Junker T, Konradi S, Schwarz L, Düring RA (2016) Occurrence and transformation of veterinary pharmaceuticals and biocides in manure: a literature review. Environ Sci Eur 28:1-25

9. Weinfurtner K (2011) Matrix parameters and storage conditions of manure. UBA-Texte 02/2011. ISSN 1862-4804. Umweltbundesamt. Dessau-Roßlau, Germany, p 54. https://www.umweltbundesamt.de/publi kationen/matrix-parameters-storage-conditions-of-manure 
10. Kreuzig R (2010) The reference manure concept for transformation tests of veterinary medicines and biocides in liquid manure. Clean-Soil Air Water 38:697-705

11. Berendsen BJA, Lahr J, Nibbeling C, Jansen LJM, Bongers IEA, Wipfler EL, van de Schans MGM (2018) The persistence of a broad range of antibiotics during calve, pig and broiler manure storage. Chemosphere 204:267-276

12. OECD (Organisation for Economic Cooperation and Development) (2002) Guideline for Testing of Chemicals No 307, Aerobic and Anaerobic Transformation in Soil. Organisation of Economic Cooperation and Development, Paris, France (original guideline, adopted 24 April 2002)

13. OECD (Organisation for Economic Cooperation and Development) (2002) Guideline for Testing of Chemicals No. 308, Aerobic and Anaerobic Transformation in Aquatic Sediment Systems. Organisation of Economic Cooperation and Development, Paris, France (original guideline, adopted 24 April 2002)

14. Junker T, Römbke J, Hennecke D, Herrchen M, Düring RA, Thiele-Bruhn S, Meinerling M, Fiebig S, Topp E, Völkel W (2016) Harmonization of environmental exposure assessment for veterinary pharmaceuticals and biocides: ring test for validation of a draft test protocol for studies on transformation in manure. UBA-Texte 80/2016. Umweltbundesamt, Dessau-Roßlau, Germany, p 231. https://www.umweltbundesamt.de/ publikationen/harmonization-of-environmental-exposure-assessment-

15. Hennecke D, Atorf C, Bickert C, Herrchen M, Hommen U, Klein M, Weinfurtner K, Heusner E, Knacker T, Junker T, Römbke J, Merrettig-Bruns U (2015) Development of a test protocol to study the transformation of veterinary pharmaceuticals and biocides in liquid manure. UBA-Texte 78/2015. Umweltbundesamt, Dessau-Roßlau, Germany, p 148. https:// www.umweltbundesamt.de/sites/default/files/medien/378/publikatio nen/texte_78_2015_development_of_a_test_protocol_to_study_the_ transformation.pdf

16. Herrchen M, Hennecke D, Junker T, Düring RA, Thiele-Bruhn S (2016) Harmonization of experimental exposure assessment for veterinary pharmaceuticals and biocides: influence of different experimental setups on observed mineralization. UBA-Texte 78/2016. Umweltbundesamt, Dessau-Roßlau, Germany. p 55. https://www.umweltbundesamt.de/publi kationen/harmonisation-of-environmental-exposure-assessment-2

17. Düring RA, Wohde M, Junker T, Hennecke D, Herrchen M, Thiele-Bruhn S (2016) Harmonization of environmental exposure assessment for veterinary pharmaceuticals and biocides: Literature review of studies on occurrence and transformation of veterinary pharmaceuticals and biocides in manure. UBA-Texte 79/2016. Umweltbundesamt, DessauRoßlau, Germany, p 51. https://www.umweltbundesamt.de/publikatio nen/harmonization-of-environmental-exposure-assessment-0
18. ISO (2005) ISO 10390: soil quality—determination of pH. International Organization for Standardization, Geneva, p 2005

19. ISO (2002) ISO 11271: Soil quality—determination of redox potential— field method. International Organization for Standardization, Geneva, $p$ 2002

20. DIN (2001) DIN EN 12880:2001-02: Characterization of sludges—determination of dry residue and water content. Deutsches Institut für Normung, Berlin

21. DIN (2001) DIN EN 12879:2001-02: Characterization of sludges-determination of the loss on ignition of dry mass. Deutsches Institut für Normung, Berlin

22. DIN (2001) DIN EN 13137:2001-12: Characterization of waste-determination of total organic carbon (TOC) in waste, sludges and sediments. Deutsches Institut für Normung, Berlin

23. DIN (1997) DIN ISO 11261 1997-05: Soil quality—determination of total nitrogen—modified Kjeldahl method. Deutsches Institut für Normung, Berlin

24. ISO (1984) ISO 5664: Water quality—determination of ammonium—distillation and titration method. International Organization for Standardization, Geneva, p 1984

25. Bickert C (2011) Biologische Aktivität in Gülle_Entwicklung und Erprobung einer Methode zur Beurteilung der mikrobiellen Aktivität in Rinder- und Schweinegülle. Diploma Thesis, FU Berlin, Fachbereich Geowissenschaften

26. EFSA (2007) Opinion on a request from EFSA related to the default Q10 value used to describe the temperature effect on transformation rates of pesticides in soil. EFSA J 622:1-32

27. Mikolasch B, Schäfer D (2006) Kinetic Introduction to the Use of KinGUI. Version 1.1 01.09.2006. Bayer CropScience AG

28. FOCUS (2014) Guidance Document on estimating persistence and degradation kinetics from environmental fate studies on pesticides in EU Registration. Report of the FOCUS Work Group on degradation kinetics. EC Document Reference SANCO/10058/2005 version 1.1, 18 December 2014. p. 434

29. Levene H (1960) Robust tests for equality of variances. In: Olkin I, Ghurye SG, Hoeffding W, Madow WG, Mann HB (eds) Contributions to probability and statistics: essays in honor of harold hotelling. Stanford University Press, Palo Alto, pp 278-292

\section{Publisher's Note}

Springer Nature remains neutral with regard to jurisdictional claims in published maps and institutional affiliations.

\section{Submit your manuscript to a SpringerOpen ${ }^{\circ}$ journal and benefit from:}

- Convenient online submission

- Rigorous peer review

- Open access: articles freely available online

- High visibility within the field

- Retaining the copyright to your article

Submit your next manuscript at $\boldsymbol{\nabla}$ springeropen.com 